\title{
Herpetofauna de serrapilheira da Reserva Florestal de Morro Grande, Cotia (SP)
}

\author{
Marianna Dixo ${ }^{1}$ \& Vanessa Kruth Verdade ${ }^{2}$ \\ Biota Neotropica v6 (n2) - http://www.biotaneotropica.org.br/v6n2/pt/abstract?article+bn00806022006 \\ Recebido em 11/1/2004 \\ Versão reformulada recebida em 22/1/2005 \\ Publicado em 01/05/2006

\begin{abstract}
${ }^{1}$ Departamento de Ecologia, Instituto de Biociências, Universidade de São Paulo, Rua do Matão, 321, travessa 14, 05508-900 São Paulo, SP (autor para correspondência: mariannadixo@yahoo.com.br).

${ }^{2}$ Departamento de Zoologia, Instituto de Biociências, Universidade de São Paulo, Rua do Matão, 321, travessa 14, 05508-900 São Paulo, SP
\end{abstract}

\begin{abstract}
Dixo, M. and Verdade, V.K. Leaf litter herpetofauna of the Reserva Florestal de Morro Grande, Cotia (SP). Biota Neotrop. May/Aug 2006 vol. 6 no. 2, http://www.biotaneotropica.org.br/v6n2/pt/abstract?article+bn00806022006. ISSN 1676-0603

We present an annotated list of anurans, lizards, and snakes registered at the Reserva Florestal de Morro Grande, Cotia, State of São Paulo. The list includes 27 anurans, five lizards and three snakes captured mainly in pitfall traps and encountered during field surveys. Eighteen species of anurans captured from pitfall traps were used to compare six areas sampled inside the Reserve, three in secondary forest and three in mature forest. The analysis showed significant differences among secondary and mature forest. We also compared the similarity of the anurofauna of the Reserve to those of six other Atlantic Forest localities inside the State. The anurofauna found at the Reserve is more similar to that found in other localities at the Atlantic plateau than those from coastal plains. The small number of reptiles specimens captured in pitfall traps precluded the same analyses made for anurans. The low abundance of these animals inside the forest limited our ability to compare different areas. There is an evident lack of information on the biology, distribution and conservation status on Brazilian herpetofauna that could be filled by inventory and monitoring of this fauna. Only natural history knowledge can lead to efficient conservation planning of these species.
\end{abstract}

Key words: herpetofauna, diversity, Atlantic Forest, conservation.

\section{Resumo}

Dixo, M. and Verdade, V.K. Herpetofauna de serrapilheira da Reserva Florestal de Morro Grande, Cotia (SP). Biota Neotrop. May/Aug 2006 vol. 6 no. 2, http://www.biotaneotropica.org.br/v6n2/pt/abstract?article+bn00806022006. ISSN 1676-0603

Apresentamos uma lista comentada de anuros, lagartos e serpentes registrados na Reserva Florestal de Morro Grande, Cotia, São Paulo. Essa lista inclui 27 espécies de anuros, cinco de lagartos e três de serpentes, capturados principalmente em armadilhas de interceptação e queda, mas também em encontros ocasionais no campo. Dezoito espécies de anuros capturadas em armadilhas de interceptação e queda foram utilizadas para a comparação de seis áreas da Reserva, três situadas em áreas de vegetação predominantemente secundária e três em áreas de vegetação predominantemente madura. As análises indicam que existe diferença significativa entre esses ambientes. Nós também comparamos a similaridade entre a anurofauna da Reserva Florestal de Morro Grande à de outras seis localidades do estado de São Paulo. A anurofauna da Reserva é mais similar àquela encontrada em outras localidades do planalto Atlântico, que àquela de localidades da baixada litorânea. O pequeno número de espécies de répteis amostrados não permitiu realizar as mesmas análises feitas para os anuros. A baixa abundância desses animais na floresta tornou a comparação entre áreas problemática. Existe uma evidente falta de informações sobre a biologia, distribuição e conservação da herpetofauna brasileira que poder ser mitigada através de inventários e monitoramento da fauna. O conhecimento da história natural, resultantes desses esforços, podem trazer argumentos sólidos para um planejamento eficiente de medidas conservacionistas.

Palavras-chave: herpetofauna, diversidade, Mata Atlântica, conservação. 


\section{Introdução}

Os anfíbios e répteis constituem o que chamamos de herpetofauna. Formam um grupo proeminente em quase todas as taxocenoses terrestres, com atualmente cerca de 5.000 espécies de anfíbios (Frost 2004) e mais de 8.000 espécies de répteis conhecidas (Uetz et al. 1995). Mais de $80 \%$ da diversidade dos dois grupos ocorre em regiões tropicais (Pough et al. 1998) cujas paisagens naturais estão sendo rapidamente destruídas pela ocupação humana.

O estado de São Paulo constitui a área mais populosa do Brasil contando com uma população de cerca de 37 milhões de habitantes. A ocupação urbana que se expande no estado desde o descobrimento resultou em grande perda de cobertura vegetal, hoje restrita a cerca de 3\% da original (Haddad 1998, Marques et al. 1998). Os ambientes florestais do planalto atlântico foram os mais prejudicados e encontram-se atualmente fragmentados e restritos a pequenas áreas protegidas no estado. Esses ambientes, historicamente parte do Domínio Morfoclimático Tropical Atlântico (Ab’Saber 1970), são extremamente ricos em espécies de anfíbios e répteis, principalmente, anuros, lagartos e serpentes, que representam aproximadamente $30 \%$, $10 \%$ e $26 \%$, do total de espécies desses grupos registradas no país (Haddad 1998, Marques et al. 1998).

Apesar de rica, a herpetofauna do estado de São Paulo é pouco conhecida, faltam levantamentos de esforço concentrado e trabalhos sobre a distribuição dessas espécies no ambiente. Nas últimas décadas, esforços nesse sentido tem revelado novas ocorrências e espécies novas originárias de fragmentos florestais próximos a áreas urbanas (e.g. Cardoso \& Haddad 1985, Verdade \& Rodrigues 2003, Verdade et al., no prelo). A herpetofauna desses fragmentos, ainda que em áreas protegidas, encontra-se provavelmente ameaçada (IUCN et al. 2004). A pressão de desmatamento é contínua, dada a expansão populacional no estado, além disso, a proximidade a centros urbanos expõe os fragmentos à retirada predatória de espécies animais e vegetais. Esses fragmentos também estão expostos aos efeitos da poluição do solo e da água por contaminantes locais, ou trazidos pelo vento e chuva a partir dos grandes centros (Davidson et al. 2001, Lopes 2001, Verdade et al., no prelo). Considerando-se ainda que declínios populacionais de anfíbios têm sido registrados em ambientes bem preservados em todo mundo, inclusive no Brasil (Heyer et al. 1988, 1990, Weygoldt 1989, Young et al. 2001), e que os fatores que os provocam são ainda desconhecidos, conhecer a fauna dos remanescentes florestais em áreas sob intensa pressão antrópica é prioritário.

Assim sendo, apresentamos a seguir uma lista preliminar das espécies de anfíbios e répteis da Reserva do Morro Grande, Cotia, com ênfase em espécies associadas à serrapilheira. Adicionalmente, apresentamos como essas espécies estão distribuídas dentro das áreas amostradas na Reserva, e como se insere a herpetofauna da área, em relação àquela conhecida para outras localidades de Mata Atlântica do estado.

\section{Material e Métodos}

\section{Amostragem da herpetofauna}

O levantamento da herpetofauna de serrapilheira foi realizado através do uso de armadilhas de interceptação e queda ("pitfall traps”, Corn 1994, Cechin \& Martins 2000). Os anuros e lagartos capturados foram marcados pela técnica de amputação de artelhos (Donnelly et al. 1994), e soltos novamente. Foram amostradas simultaneamente seis áreas da Reserva Florestal de Morro Grande, três com predominância de floresta secundária (MGA, MGB, MGC) e três com predominância de floresta madura (MGG, MGQ, MGT). O número e a disposição das armadilhas foram padronizados para as seis áreas, de forma a permitir comparações (Magurran 1988). Em cada uma das áreas de amostragem foi instalada uma linha de armadilhas contendo 11 baldes (de $60 \mathrm{l}$ ) conectados por $10 \mathrm{~m}$ de cerca-guia (com 50 cm de altura), resultando em séries de 100 m de extensão.

As amostragens dos anfíbios e répteis de serrapilheira foram realizadas em quatro campanhas de oito dias nos meses de janeiro, fevereiro e dezembro 2002 e janeiro de 2003, totalizando 32 dias nas quatro campanhas e um esforço amostral de 352 armadilhas-dia para cada área e 2112 armadilhas-dia para a Reserva. Além disso, alguns anfíbios e répteis foram amostrados através de captura ativa ou mesmo através de armadilhas de interceptação e queda fora do período amostral entre os anos de 2001 e 2004. Quando coletados, os exemplares foram depositados no Museu de Zoologia da Universidade de São Paulo. A identificação dos exemplares foi baseada nos trabalhos de descrição das espécies e consulta ao material disponível nas coleções de herpetologia do Museu de Zoologia da Universidade de São Paulo, São Paulo, SP e Museu de História Natural da Universidade de Campinas, Campinas, SP.

\section{Análise dos dados}

As comparações entre as áreas amostradas na Reserva Florestal de Morro Grande foram realizadas somente para as espécies de anuros, considerando-se apenas aquelas capturadas nas armadilhas de queda durante os 32 dias de amostragem. A presença/ausência das demais espécies de anuros, lagartos e serpentes foi utilizada apenas para a elaboração da lista das espécies da Reserva, e, no caso dos anuros, também para a comparação com outras localidades de Mata Atlântica amostradas no estado de São Paulo.

O teste-T foi utilizado para verificar se a riqueza, a abundância e a equitatividade das espécies de anuros variam significativamente entre as áreas de vegetação predominantemente secundária e as áreas de vegetação 
predominantemente madura. A equitatividade (Shannon) foi calculada para cada área amostral e para a Reserva como um todo com o auxílio do programa MVSP versão 3.1 (Kovach 1999). O teste não paramétrico de permutação ("Multi-Response Permutations Procedures”, MRPP) foi utilizado para verificar a ausência de diferença na composição da taxocenose de anuros entre as áreas de vegetação secundária e as áreas de vegetação madura (Zimmerman et al. 1985). Essas análises foram realizadas com o programa PC-ORD para Windows, versão 3.1 (McCune \& Mefford 1997). A comparação da taxocenose de serrapilheira nas diferentes áreas amostradas foi realizada através de uma análise de agrupamento. Nessa análise foram utilizados os índices de dissimilaridade de Bray-Curtis, que leva em consideração a abundância das espécies em cada sítio amostrado, e o método de agrupamento "UPGMA" (média de pares de grupos sem peso). Essa análise foi realizada com o programa MVSP, versão 3.1 (Kovach 1999). A distância geográfica das áreas amostradas e a dissimilaridade de BrayCurtis para anuros foram analisadas por regressão simples.

Comparações entre a composição faunística da Reserva Florestal de Morro Grande com outras áreas de Mata Atlântica amostradas no estado só foram realizadas com os dados obtidos para os anuros. De modo geral, lagartos e serpentes ocorrem em baixas densidades em áreas florestais e a maioria das espécies apresenta hábitos discretos (Sazima \& Haddad 1992), assim, o caráter fortuito da captura desses animais dificulta a elaboração de listas consistentes, e ainda mais, a comparação entre áreas.

A taxocenose de anuros da Reserva Florestal de Morro Grande foi comparada com a de outras seis localidades do estado de São Paulo, para as quais existem listas de espécies publicadas: Estação Biológica de Boracéia (Heyer et al. 1990), Serra do Japi, na região de Jundiaí (Haddad \& Sazima 1992), Parque Florestal do Itapetinga, em Atibaia (Giaretta et al.1999), Parque Estadual de Intervales, na região de Capão Bonito (Bertoluci 2001), Estação Ecológica JuréiaItatins, na região de Peruíbe (Pombal \& Gordo 2004) e Reserva Biológica de Paranapiacaba (Verdade et al., no prelo). Sabendo que a comparação da composição de taxocenoses entre áreas pode ser avariada e muitas vezes irreal em decorrência de diferenças no esforço amostral, no tamanho e características da área e também, de diferenças nos conceitos taxonômicos entre os autores (Pombal 1995), adotamos alguns critérios para minimizar esses problemas. Foram retiradas das listas espécies consideradas como grupo (gr.) e affinis ( aff.). Aquelas citadas como confer ( $c f$.) foram mantidas como se determinadas (e.g. Eleutherodactylus $c f$. nigriventris $=E$. nigriventris). Além disso, foram retiradas espécies não contempladas pelo método de amostragem utilizado na Reserva, como aquelas de hábito arborícola, ou espécies terrestres associadas a riachos. Também foram excluídas da análise espécies associadas a ambientes abertos e que são encontradas em ambiente florestal apenas eventualmente. Diferenças quanto ao esforço amostral entre essas localidades são intensas e foram consideradas na interpretação dos resultados.

A partir desses dados foi realizada uma análise de agrupamento, utilizando o índice de similaridade de Sorensen (Wolda 1981), no qual são considerados apenas presença e ausência de cada espécie nas áreas, e o método de agrupamento "WPGMA" (média de pares de grupos com peso; Sneath \& Sokal 1973). Este método de agrupamento foi escolhido devido às diferenças nos tamanhos das amostras (nesse caso, número de espécies por área). A análise foi feita com o programa MVSP, versão 3.1 (Kovach 1999).

\section{Resultados e Discussão}

\section{Anuros}

Considerando-se as capturas em armadilhas de interceptação e queda e os encontros fortuitos, foram registradas 27 espécies de anuros na Reserva do Morro Grande, distribuídos entre as famílias Brachycephalidae (2spp.), Bufonidae (3spp.), Hylidae (6spp.), Leptodactylidae (13spp.), Microhylidae (2spp.) e Ranidae (1sp.) (Tabela 1).

A representatividade das famílias na amostra seria típica de áreas de florestas neotropicais, não fosse a presença de uma espécie da família Ranidae. Rana catesbeiana é originária da América do Norte, introduzida no território nacional para criação e consumo alimentar. A fuga de exemplares de ranários e o estabelecimento de populações naturais tem se tornado um importante problema de conservação, principalmente no sudeste e sul do país. Também é interessante a presença de um número muito maior de leptodactilídeos em relação ao número de hilídeos. De maneira geral, o número de hilídeos em áreas de Mata Atlântica se iguala ou supera o de leptodactilídeos. Faltam também representantes de outras famílias, como os centrolenídeos, de hábito predominantemente arborícola. Esse viés é certamente resultado da metodologia de coleta aplicada. A anurofauna da Reserva foi amostrada basicamente por procura passiva, através de armadilhas de interceptação e queda, que não contempla grupos de hábito arborícola. Não foram empreendidas horas de busca ativa em trilhas e corpos d'água durante a noite, o que certamente elevaria o número dessas espécies.

Desconsiderando-se Rana catesbeiana, 17 espécies (cerca de 65\% do total) apresentam distribuição ampla dentro do Domínio Atlântico, ocorrendo tanto na baixada litorânea como em áreas mais altas nas serras e planalto atlântico. Cinco espécies (19\%), apresentam distribuição restrita a algumas áreas de Mata Atlântica dentro dos limites políticos de apenas um ou dois estados do sudeste do Brasil. As outras quatro espécies (16\%), encontram-se amplamente distribuídas dentro e fora dos limites do Domínio Tropical 
Atlântico (Ab’Saber, 1970)(Tabela 1). Como tipicamente encontrado em áreas de florestas tropicais úmidas, muitas espécies (38\%) apresentam reprodução terrestre, utilizando refúgios na serrapilheira para deposição de ovos, algumas (12\%) apresentam reprodução associada a bromélias, e a maioria (50\%) apresenta reprodução associada a ambientes aquáticos (Tabela 1 ).

Nenhuma das espécies registradas na Reserva encontra-se na lista nacional de espécies ameaçadas do IBAMA (2003) ou nas listas de espécies ameaçadas de São Paulo (São Paulo 1998), Minas Gerais (Machado et al. 1998), Rio de Janeiro (Bergalo et al. 2000) e Paraná (Mikich \& Bernils 2004). Chiasmocleis leucosticta aparece na listagem do Paraná como DD, que representa falta de informações populacionais que permitam classificar a situação da espécie nas categorias de ameaça. Apresentamos a seguir comentários sucintos sobre a aparência, biologia e distribuição dessas espécies. A classificação dos hilídeos citados segue a proposta de Faivovich e colaboradores (2005). As medidas apresentadas como tamanho das espécies referem-se ao comprimento rostro-cloacal.

Brachycephalus ephippium (Spix) é uma espécie de pequeno porte (cerca de $2 \mathrm{~cm}$ ) de coloração amarelo ouro. Apresenta redução de dedos e artelhos e uma placa óssea subcutânea que recobre parte do dorso e cabeça. Pode ser encontrado em grandes concentrações sobre a serrapilheira durante o dia no período reprodutivo. Os ovos são depositados em meio às folhas no solo e o desenvolvimento é direto (Izecksohn \& Carvalho-e-Silva 2001). Trata-se de um complexo de espécies que está sendo atualmente estudado e deve ser dividido em breve (J.P. Pombal Jr., dados não publicados). A distribuição atual da espécie abrange os estados da Bahia, Espírito Santo, Rio de Janeiro, São Paulo e Paraná (Frost 2004).

Brachycephalus hermogenesi (Giaretta \& Sawaya) até recentemente no gênero Psyllophryne (Kaplan 2002), é uma espécie de rã de pequeno porte, considerada um dos menores vertebrados terrestres (Estrada \& Hedges 1996), com adultos que não chegam a atingir $1 \mathrm{~cm}$. Apresenta redução de dedos e artelhos, o dorso é marrom alaranjado com uma mancha mais escura central em forma de $\mathrm{X}$, o ventre e a lateral do corpo são escuros e os olhos são relativamente grandes, de coloração vermelha. São terrestres e permanecem ativos durante o dia e também à noite. As fêmeas botam um único ovo por vez em meio às folhas e, a julgar pelo tamanho do ovo, o desenvolvimento é direto (Giaretta \& Sawaya 1998). A espécie até recentemente era conhecida apenas para áreas de Mata Atlântica da divisa dos estados de São Paulo e Rio de Janeiro, atualmente foi registrada também em áreas do planalto de São Paulo (V.K.Verdade et al., dados não publicados).

Bufo ornatus Spix é uma espécie de porte médio (cerca de $8 \mathrm{~cm}$ ), muito comum em áreas de mata, de coloração geral marrom e freqüentemente com uma linha clara vertebral acompanhada lateralmente por três pares de manchas negras. Os jovens dessa espécie são diurnos e os adultos crepusculares ou noturnos (Guix et al. 1998). A reprodução ocorre em ambientes aquáticos com pouca correnteza, utilizando-se também de ambientes não naturais. Os ovos são depositados em um cordão gelatinoso e presos à vegetação aquática (Pombal \& Gordo 2004). O girino é pequeno, negro e costuma formar cardumes com atividade noturna (Haddad \& Sazima 1992). Pode ser encontrado do nível do mar até cerca de 1000m de altitude em áreas de Mata Atlântica, do sul do estado do Espírito Santo, através do Rio de Janeiro e São Paulo, até o norte do Paraná e possivelmente o nordeste da Argentina (Baldissera et al. 2004).

Bufo ictericus Spix é uma espécie de grande porte (cerca de $20 \mathrm{~cm}$ ), conhecida popularmente como sapo-cururu. As fêmeas são maiores que os machos e apresentam dorso manchado de marrom escuro; os machos em geral apresentam coloração amarelada (Heyer et al. 1990). Em ambos os sexos ocorre uma glândula de veneno bastante desenvolvida localizada atrás dos olhos (glândula parotóide). É uma espécie noturna, que pode ser encontrada em áreas de mata e também em áreas perturbadas. Reproduz em ambientes lênticos ou de fraca correnteza em área aberta; a desova é depositada envolta em um cordão gelatinoso e em geral ancorada na vegetação submersa. A espécie é comum tanto no litoral como em áreas serranas e planálticas dos estados do sudeste e sul do Brasil até o leste do Paraguai (Guix et al. 1998).

Dendrophryniscus brevipollicatus Jimenez de la Espada é uma espécie de pequeno porte (cerca de $2 \mathrm{~cm}$ ), com dorso amarronzado e com um desenho central em forma de X ou ampulheta. É uma espécie que pode ser encontrada em atividade tanto durante o dia como à noite, encontrada em áreas florestadas com grande quantidade de bromélias (Izecksohn \& Carvalho-e-Silva 2001). A reprodução ocorre em bromélias, terrestres ou próximas ao solo, onde são depositados os ovos e os girinos se desenvolvem (Pombal \& Gordo 2004). A espécie pode ser encontrada em áreas florestadas do sudeste e sul do Brasil (Guix et al. 1998).

Dendropsophus microps Peters é uma perereca de pequeno porte (cerca de $3 \mathrm{~cm}$ ), que apresenta a região posterior da coxa e partes internas dos pés e região inguinal com coloração laranja contrastante com a cor de fundo, que só pode ser observada quando o animal se locomove. É encontrada durante a noite, utiliza para reprodução ambientes lênticos ou de fraca correnteza e de água límpida (Lutz 1973). É encontrada na Floresta Atlântica do sudeste e sul do Brasil, em áreas montanhosas e baixadas, nos estados do Espírito Santo, Rio de Janeiro, São Paulo e Paraná (Heyer 1980).

Flectonotus fissilis (Miranda-Ribeiro) é uma espécie de pequeno porte (cerca de $3 \mathrm{~cm}$ ) de coloração amarronzada com linhas escuras no ângulo do focinho e uma faixa escura ao redor do pulso. É noturna e vive associada a bromélias. As fêmeas carregam os ovos no dorso, protegidos por uma dobra 
de pele que se desenvolve após a postura e fixação dos ovos. A eclosão dos girinos se dá em estágios avançados do desenvolvimento no dorso da fêmea. Podem alimentar-se exclusivamente das reservas de vitelo, mas são levados pela fêmea até os reservatórios de água nas axilas de bromélias, onde terminam o desenvolvimento. Ocorrem em áreas de florestas úmidas do sudeste do Brasil, nos estados de São Paulo e Rio de Janeiro (Duellman \& Gray 1983).

Hypsiboas bischoffi Boulenger é uma perereca de médio porte (cerca de $5 \mathrm{~cm}$ ) característica por apresentar faixas longitudinais ao longo do dorso. A superfície posterior da coxa é violácea com manchas escuras e a parte externa da tíbia apresenta uma faixa esverdeada. Pode ser encontrada durante à noite na vegetação marginal a corpos d’água dentro ou na borda de mata, em áreas altas. Os ovos são depositados em ambientes lênticos, onde os girinos se desenvolvem (Lutz 1973). Ocorre na Mata Atlântica entre o Rio de Janeiro e o Rio Grande do Sul em áreas florestadas montanhosas (Frost 2004).

Scinax alter (Lutz) é uma espécie de pequeno porte (cerca de $3 \mathrm{~cm}$ ), de dorso amarronzado, levemente granular, com duas faixas aproximadamente paralelas mais escuras no dorso. É encontrada ativa durante a noite na vegetação marginal de brejos e poças, onde deposita os ovos e os girinos se desenvolvem. São mais comuns na baixada litorânea, tendo sido registradas nos estados de Pernambuco a Santa Catarina (Pombal \& Gordo 2004).

Scinax fuscovarius (A. Lutz) é uma perereca de médio porte (cerca de $5 \mathrm{~cm}$ ), de coloração acinzentada com manchas escuras no dorso, que variam em quantidade e padrão, e coloração amarelada na cintura. É uma espécie noturna, muito comum em áreas abertas, encontrada inclusive dentro de habitações. A reprodução ocorre em poças temporárias em áreas abertas (Lutz 1973). O grupo apresenta taxonomia complexa, com diversas populações associadas a um mesmo nome. Encontra-se amplamente distribuída no sul e sudeste do Brasil, leste da Argentina, Paraguai e Bolívia (Frost 2004).

Scinax perpusillus (A. Lutz \& B. Lutz) é uma espécie de tamanho pequeno (cerca de $2 \mathrm{~cm}$ ), e coloração acinzentada, associada a bromélias. Os machos são territoriais e escolhem uma bromélia, de onde vocalizam. Os ovos são depositados na água acumulada na axila das bromélias, onde os girinos se desenvolvem (Oliveira \& Navas 2004). Trabalhos ainda não publicados apontam indícios de que sob esse nome encontram-se populações de espécies distintas. A distribuição de $S$. perpusilllus, na configuração válida atualmente, inclui áreas da baixada litorânea, serras e planalto dos estados do Espírito Santo, Rio de Janeiro e São Paulo (Peixoto 1987)

Adenomera marmorata Steindachner é uma espécie de pequeno porte (cerca de $2 \mathrm{~cm}$ ), com dorso de coloração esverdeada e manchas escuras, alguns indivíduos podem apresentar faixas laterais de coloração laranja. É uma espécie terrestre, típica de borda de florestas, permanecendo ativa durante dias nublados. A reprodução ocorre em pequenas tocas no solo, onde os ovos são depositados em ninhos de espuma. Os girinos desenvolvem-se na toca até a metamorfose, mantidos apenas pelas reservas de vitelo (Heyer 1973). Sob esse nome, também existem indícios de que existam populações de espécies distintas envolvidas. Segundo a configuração atual, A. marmorata pode ser encontrada em áreas de Mata Atlântica do sudeste e sul do Brasil, nos estados do Rio de Janeiro, São Paulo, Paraná e Santa Catarina (Frost 2004).

Crossodactylus caramaschii Bastos \& Pombal é uma espécie de pequeno porte (cerca de 2,5 cm), com dorso marrom com manchas lineares escuras. É uma espécie diurna, que vive associada a riachos de fundo arenoso em áreas florestais. A reprodução ocorre nesses ambientes, onde são depositados os ovos e os girinos se desenvolvem. A distribuição da espécie inclui áreas de Mata Atlântica de alguns municípios do sul e sudeste do estado de São Paulo (Bastos \& Pombal 1995).

Cycloramphus acangatan Verdade \& Rodrigues é uma espécie de médio porte (cerca de $3,5 \mathrm{~cm}$ ), de coloração marrom escuro ou avermelhada, com dorso uniforme ou apresentando manchas claras irregulares. A cabeça apresenta musculatura bastante desenvolvida e os membros são curtos, o que caracteriza o aspecto típico da espécie. Apresenta hábitos semi-fossoriais, podendo ser encontrada escondida sob as folhas ou troncos caídos em áreas florestadas. A desova é depositada em tocas em barrancos. Os girinos eclodem em estágio avançado de desenvolvimento e permanecem na toca, alimentando-se exclusivamente da reserva de vitelo do ovo até a metamorfose (V.K. Verdade, dados não publicados). A distribuição da espécie inclui áreas de Mata Atlântica do planalto e de encosta, nas proximidades da Serra de Paranapiacaba (Verdade \& Rodrigues 2003).

Eleutherodactylus binotatus (Spix) é uma espécie que chega a atingir cerca de $6 \mathrm{~cm}$ de comprimento rostrocloacal. Apresenta coloração variável e freqüentemente dois pontos escuros no dorso, próximos à região sacral. Caracteriza-se pela presença do dedo I muito maior que o dedo II e expansões digitais pouco desenvolvidas. Comum em áreas de mata, pode ser encontrada em atividade também durante o dia na serrapilheira. Os ovos são depositados em meio às folhas e o desenvolvimento é direto (Heyer et al. 1990). A espécie apresenta ampla distribuição nas áreas de Mata Atlântica do sudeste do Brasil (타ost 2004).

Eleutherodactylus guentheri (Steindachner) é uma espécie de porte médio (cerca de $4 \mathrm{~cm}$ ), característica por apresentar membros posteriores muito longos. O padrão de coloração é bastante variável e em geral inclui uma mancha escura sobre o tímpano e uma barra segmentada ou contínua na região anterior da tíbia. É comum em áreas florestadas sendo encontrado movimentando-se na serrapilheira 
também durante o dia. Os ovos são depositados em tocas no solo e o desenvolvimento é direto (Lynn \& Lutz 1946). Pode ser encontrado em áreas florestadas nos estados do sudeste e sul do país e também em Misiones na Argentina (Heyer 1984).

Eleutherodactylus juipoca Sazima \& Cardoso é uma espécie de pequeno porte (cerca de $3 \mathrm{~cm}$ ), com dorso de coloração e padrões complexos envolvendo tonalidades de verde, vermelho, marrom e branco. Pode ser encontrado em atividade durante dias nublados e à noite. Ocupa ambientes de borda de mata e capoeira. A reprodução é terrestre, os ovos são depositados no chão entre moitas e arbustos e o desenvolvimento é direto. Possui ampla distribuição, incluindo os estados de São Paulo, Minas Gerais e Goiás (Sazima \& Cardoso 1978, Bastos \& Pombal 2001).

Eleutherodactylus sp. (gr. lacteus) é uma espécie de Eleutherodactylus de tamanho pequeno (cerca de $3 \mathrm{~cm}$ ), com expansões digitais muito desenvolvidas. A pele do dorso é rugosa e o padrão de coloração complexo. A espécie que dá nome ao grupo foi descrita por Miranda-Ribeiro (1922) e parece englobar um complexo de espécies que apresentam em comum disco reduzido no primeiro dedo (J. Pombal Jr. comun. pess.). A distribuição do grupo inclui áreas de Mata Atlântica do sudeste do Brasil.

Eleutherodactylus parvus (Girard) é uma espécie de pequeno porte (cerca de $2 \mathrm{~cm}$ ), com padrão de coloração muito variável. Apresenta tipicamente uma mancha escura na região da cloaca e parte posterior da coxa e a extremidade dos artelhos terminam em seta. É encontrado em atividade na serrapilheira de áreas florestadas durante o dia e à noite. Os ovos são depositados em meio à serrapilheira e o desenvolvimento é direto (Haddad \& Sazima 1992). A distribuição da espécie inclui áreas de Mata Atlântica do sudeste do Brasil (Frost 2004).

Leptodactylus ocellatus (Linnaeus) é uma rã de grande porte (cerca de $12 \mathrm{~cm}$ ), com dorso com manchas arredondadas dispersas, sendo comum uma mancha triangular escura entre os olhos e faixas glandulares longitudinais. Os machos são maiores que as fêmeas e apresentam braços muito desenvolvidos. A espécie é noturna, comumente encontrada dentro da água, em ambientes diversos. As desovas são depositadas em um ninho de espuma e após a eclosão, os girinos formam grandes cardumes. A fêmea permanece nas proximidades e protege a prole (Vaz-Ferreira et al. 1999). Encontra-se amplamente distribuída no Brasil, Uruguai, Paraguai e Argentina (Frost 2004). Trabalhos recentes a partir de dados moleculares têm revelado indícios de que sob esse nome existam populações de espécies diferentes (W.R. Heyer \& R. De Sá, dados não publicados).

Macrogenioglottus alipioi Carvalho é uma espécie de grande porte (cerca de $10 \mathrm{~cm}$ ), com focinho curto, coloração geral escura com um marmoreado branco no dorso e grupos granulares na região dorsolateral. É uma espécie de hábitos noturnos, que pode ser encontrada na serrapilheira de áreas de mata. Reproduz após fortes chuvas em poças formadas pelo transbordamento de riachos dentro da mata. Os ovos permanecem no fundo dessas poças, os girinos são pouco móveis, provavelmente como adaptação contra predação (Abravaya \& Jackson 1978). É conhecida para áreas de Mata Atlântica do estado da Bahia até São Paulo (Frost 2004).

Physalaemus cuvieri Fitzinger é uma espécie de pequeno porte (cerca de $3 \mathrm{~cm}$ ), que apresenta padrões de coloração e textura do dorso muito variáveis. Os padrões mais comuns são aqueles em que o dorso é liso e acinzentado, com uma mancha central em forma de ômega, e dorso acinzentado com cordões longitudinais escuros. Em vida, os exemplares apresentam uma coloração alaranjada ou avermelhada na região inguinal, na região posterior da coxa e próximo às axilas. São encontrados em atividade durante a noite, próximos a ambientes aquáticos lênticos em áreas abertas. Os ovos são depositados em ninhos de espuma, ancorados à vegetação (Haddad \& Sazima, 1992). Possui distribuição geográfica bastante ampla, ocorrendo no nordeste, centro-oeste, sudeste e sul do Brasil, em Misiones e Entre Rios na Argentina e no leste do Paraguai (Frost 2004).

Physalaemus olfersii (Lichtenstein \& Martens) é uma rã de pequeno porte (cerca de $3 \mathrm{~cm}$ ), de focinho acuminado, que apresenta uma faixa negra bordeada superiormente de branco, estendendo-se lateralmente dos olhos à região inguinal. Encontra-se ativa durante a noite, os machos vocalizam no chão, próximos a corpos d’água em áreas abertas ou borda de mata. Os ovos são depositados em um ninho de espuma na beira da água (Heyer et al. 1990). Os girinos são conhecidos, mas não foram ainda formalmente descritos. Pode ser encontrada em áreas de Mata Atlântica do sudeste e sul do Brasil (Frost 2004).

Proceratophrys boiei (Wied-Neuwied) é uma espécie de porte médio (cerca de $7 \mathrm{~cm}$ ), que possui apêndices de pele sobre as pálpebras. A coloração e o padrão assemelhamse às folhas mortas da serrapilheira. Pode ser encontrado durante o dia e à noite em meio às folhas da serrapilheira. Os ovos são depositados sob as folhas submersas em poças e remansos de riachos no interior da mata (Cochran 1955). A distribuição inclui áreas de Mata Atlântica dos estados de Pernambuco a Santa Catarina (Frost 2004).

Chiasmocleis leucosticta (Boulenger) é uma espécie de pequeno porte (cerca de $2 \mathrm{~cm}$ ) de dorso escuro e ventre com manchas claras. Estão presentes, principalmente nos machos, pequenos espinhos espalhados pelo corpo, que podem ser visualizados apenas sob lupa. Machos diferem da fêmea por apresentar membranas mais extensas entre os artelhos. É noturna e fossorial, encontrada no interior de áreas florestadas. A reprodução é explosiva e ocorre após chuvas fortes. Os ovos são depositados em poças temporárias em meio a bolhas de ar produzidas pelo casal 
em amplexo (Haddad \& Hödl 1997). Pode ser encontrada em áreas de Mata Atlântica dos estados de São Paulo a Santa Catarina (Cruz et al. 1997).

Myersiella microps (Duméril \& Bibron) é uma espécie de pequeno porte (cerca de $3 \mathrm{~cm}$ ), considerada rara. Apresenta coloração geral escura e focinho afilado. Pode ser encontrada em meio a serrapilheira e sob troncos caídos e pedras de florestas úmidas. Os ovos são depositados entre a serrapilheira e o solo e o desenvolvimento é direto. Pode ser encontrada em áreas de Mata Atlântica dos estados do Espírito Santo, Rio de Janeiro e São Paulo (Izecksohn 1971).

Rana catesbeiana Shaw é uma espécie de grande porte, que chega a atingir $15 \mathrm{~cm}$. A coloração geral é esverdeada, a pele é lisa e estão presentes extensas membranas entre os artelhos. É uma espécie originária da America do Norte, introduzida no Brasil na década de 60 para criação e comercialização de carne. Tem se espalhado pelo território nacional através de ranários, de onde conseguem fugir. Encontra-se sempre associada a ambientes aquáticos. No Brasil reproduz duas vezes ao ano e pode chegar a depositar até cerca de 20.000 ovos por desova (Vizotto 1984).

\subsection{Abundância e distribuição}

Dentre as 18 espécies capturadas em armadilha de interceptação e queda (Figura 1, Tabela 1), Bufo ornatus foi a mais abundante, representando $60 \%$ dos indivíduos amostrados, seguido de Cycloramphus acangatan (10\%) e Bufo ictericus (5\%). Brachycephalus ephippium, Dendrophryniscus brevipollicatus, Physalaemus cuvieri e Eleutherodactylus juipoca são as espécies menos abundantes na Reserva, provavelmente por diferentes razões. As duas primeiras encontram-se supostamente distribuídas de maneira desigual em áreas florestadas, variando de acordo com certas características ambientais, como por exemplo, a presença de bromélias no caso de $D$. brevipollicatus. Eleutherodactylus juipoca, apesar de ser uma espécie considerada florestal, é tipicamente encontrada em clareiras e portanto pouco freqüente no interior da mata (Haddad 1998). Já P.cuvieri é uma espécie originária de áreas abertas, que não costuma ocupar ambientes florestais (Haddad 1998). A espécie é bastante comum nas áreas de cultivo da região e está invadindo os fragmentos de mata que circundam a Reserva (M. Dixo, observação pessoal).

Três espécies fossoriais foram capturadas, Chiasmocleis leucosticta, Myersiella microps e Cycloramphus acangatan. Cycloramphus acangatan foi capturada em número elevado e em diversas áreas, o que pode ser uma indicação de que sua distribuição seja uniforme no ambiente. Inversamente, a presença de 4 indivíduos de C. leucosticta capturados em uma das áreas (MGG) e 23 indivíduos de $M$. microps capturados em outra (MGT), pode ser um indício de que essas espécies ocorram em manchas no ambiente.
A ausência de Eleutherodactylus binotatus e Eleutherodactylus gr. lacteus na amostra feita pelas armadilhas de interceptação e queda pode ser creditada a um viés do método, uma vez que essas espécies são capazes de escapar do balde, seja pulando ou escalando-o (M. Dixo, observação pessoal). Sendo assim, a abundância de $E$. guentheri, E. juipoca e E. parvus também podem estar subestimadas. Com exceção de Eleutherodactylus gr. lacteus, vários exemplares dessas três espécies foram observados ativamente durante o período de amostragem (M. Dixo, observação pessoal).

É interessante salientar que Macrogenioglottus alipioi, espécie considerada rara (Haddad 1998), foi bem amostrada para a Reserva, com 18 exemplares capturados, o que indica que não é tão rara como imaginava-se e que armadilhas de interceptação e queda parecem potencializar a coleta dessa espécie.

Algumas espécies, Brachycephalus hermogenesi, Bufo ornatus, Cycloramphus acangatan, Chiasmocleis leucosticta e Myersiella microps, parecem mais abundantes em áreas de mata predominantemente madura (MGG, MGQ, MGT). Todas elas, exceto B. ornatus, apresentam ovos que se desenvolvem em ambiente terrestre (Tabela 1). A umidade pode ser um fator limitante para o desenvolvimento dessas espécies e, talvez, a umidade relativa do ar, supostamente maior dentro das florestas maduras, seja um dos fatores que favoreça sua maior abundância. Já a grande abundância de Bufo ornatus pode estar relacionada à maior quantidade de sítios reprodutivos presentes nas áreas agrícolas adjacentes as áreas de vegetação madura da Reserva, principalmente as MGG e MGQ, que estão muito próximas da borda da mata. As áreas MGA, MGB e MGC, apesar de secundárias, encontram-se em uma região mais nuclear da Reserva.

Inversamente, as espécies que parecem preferir áreas predominantemente secundárias (MGA, MGB, MGC), como Leptodactylus ocellatus, Physalaemus olfersii e Macrogenioglottus alipioi, usam ambiente aquático para se reproduzir. Assim sendo, essas espécies não seriam tão dependentes da umidade da mata para o desenvolvimento de seus ovos e girinos. Adenomera marmorata é a única espécie a não utilizar ambientes aquáticos para reprodução, que também parece preferir áreas predominantemente secundárias. Pelo fato da desova dessa espécie ser depositada em ninhos de espuma dentro de tocas, sua tolerância à variação de umidade no interior da mata pode ser maior.

A riqueza observada em cada área variou de oito a 11 espécies, totalizando 18 espécies nas seis áreas amostradas na Reserva (Tabela 1). Quando comparadas as áreas de vegetação predominantemente secundária e as áreas de vegetação predominantemente madura, a riqueza não variou significativamente $(\mathrm{t}=-0,35, p=0,741)$. Por outro lado, uma menor abundância ( $\mathrm{t}=-7,06, p=0,002)$ e uma maior equitatividade $(\mathrm{t}=4,42, p=0,012)$ de anuros foi encontrada nas áreas de vegetação predominantemente secundária do 
que nas áreas de vegetação predominantemente madura. Essa variação de abundância e equitatividade ocorre graças a Bufo ornatus, que corresponde a $72 \%$ dos anuros amostrados nas áreas de vegetação madura (Tabela 1).

As áreas de mata secundária e madura são mais similares entre si, que uma com a outra. A análise de agrupamento considerando a abundância das espécies de anuros de serrapilheira em cada área separou-as em dois grandes grupos, um unindo MGA e MGB e estes com MGC, e outro unindo MGG e MGQ, e estes com MGT (Figura 2). A dissimilaridade entre as áreas amostradas está positivamente relacionada à distância geográfica entre elas $\left(\mathrm{R}^{2}=0,69\right.$; $p<0,001$; Figura 3). A composição da taxocenose de anuros de serrapilheira entre as áreas de vegetação secundária e as áreas de vegetação madura é significativamente diferente (MRPP; $p=0,022)$. Esses resultados não esclarecem se a variação na composição da taxocenose de anuros entre as áreas MGA, MGB, MGC e as áreas MGG, MGQ, MGT é uma resposta ao estado preservação da mata, secundária versus madura, ou se é resposta à distância geográfica entre as áreas, uma vez que as áreas de vegetação semelhante são também mais próximas entre si. Na realidade, parece haver uma interação entre as respostas ao estado de preservação das matas e a distância geográfica para algumas espécies. Brachycephalus hermogenesi e Cycloramphus acangatan por exemplo, ocorrem tanto em áreas maduras como em secundárias, mas mostram uma preferência clara pela mata madura. Quando presentes nas áreas de mata secundária, ocorrem em maior número ou somente, na área MGC, a mais próxima geograficamente das áreas de floresta madura.

Em relação a outras localidades de áreas de Mata Atlântica, a lista de espécies apresentada para a Reserva de Morro Grande está subestimada em decorrência do método de amostragem aplicado. As duas áreas de Mata Atlântica mais intensamente amostradas no estado de São Paulo e talvez, no território nacional, são a Estação Biológica de Boracéia e a Reserva Biológica de Paranapiacaba. Essas áreas têm sido amostradas durante anos e as listas de espécies encontradas nesses locais chegam a 70 (Heyer 1990, Bertoluci 1997, Verdade et al. no prelo).

Outras listas publicadas para localidades do estado de São Paulo incluem a Fazenda Intervales, na região de Capão Bonito, a Estação Ecológica Juréia-Itatins, na região de Peruíbe, a Serra do Japi, na região de Jundiaí e o Parque Florestal do Itapetinga, em Atibaia. Essas áreas foram amostradas por períodos variados, como parte de diversos projetos de pesquisa e contam respectivamente com 48, (Bertoluci 2001, Verdade \& Rodrigues 2003), 31 (Pombal \& Gordo 2004), 24 (Haddad \& Sazima 1992) e 16 espécies de anuros ( Giaretta et al. 1999). A riqueza encontrada na Reserva do Morro Grande (27spp) condiz com o esforço amostral empregado, mas amostragens que incluíssem procura ativa, além das armadilhas de interceptação e queda, poderiam revelar números muito maiores.
Ao mesmo tempo que a utilização somente de armadilhas de interceptação e queda causa um viés na riqueza total da área, esse método amostra eficientemente a anurofauna associada à serrapilheira. Se considerarmos a lista das espécies de anuros tipicamente encontradas nesse ambiente, excluindo-se aquelas estritamente associadas a outros sítios, como riachos por exemplo (e.g. algumas espécies de Cycloramphus, Megaelosia spp. e Thoropa spp.) a situação se altera. A reserva passa a ser uma das áreas do estado com anurofauna associada à serrapilheira mais bem amostrada (18spp.), perdendo em número de espécies, somente para Boracéia e Paranapiacaba (ambas com 25spp.).

A similaridade entre a anurofauna de serrapilheira dessas seis áreas (Boracéia, Paranapiacaba, Intervales, Serra do Japi, Atibaia e Juréia) e a Reserva do Morro Grande é relativamente alta, como indicado na Figura 4A. A análise de agrupamento separa inicialmente a Estação Ecológica da Juréia das demais. Esse resultado concorda com as observações de Pombal \& Gordo (2004) referentes à maior similaridade de anurofauna da Estação a outras áreas da baixada litorânea, do que a áreas mais próximas da Serra e do Planalto Atlântico. Por ser uma área da baixada litorânea, a Estação apresenta condições topográficas e climáticas diferentes daquelas encontradas em áreas de maior altitude, que refletem-se nas diferenças na composição de espécies.

As cinco áreas restantes e a Reserva do Morro Grande formam um grupo, do qual separa-se inicialmente outro, formado pela Serra do Japi e Atibaia. Essas duas localidades são as áreas mais interiorizadas dentre as amostradas (Figura 4B) e encontram-se em uma área de transição entre a Mata Atlântica senso estrito e as florestas semidecíduas do interior do planalto (Leitão Filho 1982), nas proximidades da Serra da Mantiqueira. As diferenças encontradas na anurofauna em relação àquela do grupo formado por Boracéia, Paranapiacaba, Intervales e Morro Grande podem ser reflexo de um ambiente mais seco e sazonal, além de serem as localidades geograficamente mais próximas . A distância geográfica parece não ser o fator mais importante nesse caso, pois a área mais próxima da Serra do Japi e Atibaia é a Reserva do Morro Grande.

Boracéia, Paranapiacaba, Intervales e Morro Grande estão associadas em um grupo com similaridade muito alta. Dentro desse grupo, as áreas encontram-se unidas duas a duas: Boracéia-Paranapiacaba e Intervales-Morro Grande. Essa associação parece não seguir um padrão de distância geográfica, dada a distância entre a Reserva do Morro Grande e Intervales. Os agrupamentos observados podem ser reflexo de diferenças ambientais decorrentes do posicionamento geográfico das quatro localidades envolvidas. Boracéia e Paranapiacaba encontram-se na escarpa de Serra do Mar, mais próximas do litoral e provavelmente mais úmidas, recebendo diretamente a umidade que vem do oceano. Morro Grande e Intervales 
encontram-se mais interiorizadas no Planalto Atlântico e apresentam condições de umidade e temperatura diferenciadas em decorrência também da continentalidade.

O padrão de similaridade obtido entre a anurofauna de serrapilheira dessas sete localidades parece coerente com as principais formações geomorfológicas do estado de São Paulo, apresentando agrupamentos que refletem diferenças encontradas entre o litoral (Juréia), a Serra da Mantiqueira (Serra do Japi e Atibaia), Serra do Mar (Boracéia e Paranapiacaba) e Planalto Atlântico (Morro Grande e Intervales). No entanto essas relações deve-se, em alguns casos à presença de espécies reconhecidamente de distribuição restrita (e.g. Eleutherodactylus hoehnei, E. nigriventris, e Paratelmatobius poecilogaster em Paranapiacaba e Boracéia), fossoriais (e.g. Chiasmocleis leucosticta em Intervales e Morro Grande) ou ausências. Sabe-se que existem lacunas no esforço de coleta mesmo em localidades próximas aos grandes centros urbanos e, em se tratando de animais associados à serrapilheira, normalmente de difícil captura e, ainda mais raros se a amostragem não inclui armadilhas de interceptação e queda, as ausências devem ser analisadas com cautela, pois podem ser artefatos. Tanto esforços direcionados à coleta de anuros que incluam armadilhas de interceptação e queda em Intervales, Serra do Japi e Intervales, como uma análise de agrupamento incluindo a lista completa de anuros de cada localidade poderiam alterar a configuração das relações apresentadas na Figura 4B.

\section{Lagartos e serpentes}

Foram registrados na área da Reserva Florestal de Morro Grande um total de cinco espécies de lagartos, pertencentes às famílias Gymnophthalmidae (3spp), Leiosauridae (1sp) e Teiidae (1sp) e três espécies de serpentes, uma de cada uma das famílias mais conhecidas de serpentes brasileiras, Colubridae, Elapidae e Viperidae (Tabela 2).

Todas as espécies encontradas na Reserva são típicas de áreas florestadas do Domínio Atlântico, com distribuição ampla no sudeste do Brasil. Tupinambis merianae é a espécie que tolera ambientes mais abertos, vivendo de maneira geral em bordas e clareiras de mata. Todos os lagartos e serpentes registrados apresentam hábito terrestre. Enyalius perditus é considerado semi-arborícola e utiliza a serrapilheira para forragear e é comumente capturado em armadilhas de interceptação e queda. A presença de três espécies da família Gymnophthalmidae também parece ser um reflexo do método de amostragem. Esses lagartos apresentam em geral tamanho muito reduzido sendo de difícil captura manual em meio à serrapilheira.

Nenhuma das espécies registradas na Reserva encontra-se na lista brasileira de espécies ameaçadas elaborada pelo IBAMA (2003), ou nas listas de espécies ameaçadas dos estados de São Paulo (São Paulo 1998),
Minas Gerais (Machado et al. 1998), Rio de Janeiro (Bergalo et al. 2000) e Paraná (Mikich \& Bernils 2004). Mas três lagartos (Colobodactylus taunayi, Ecpleopus gaudichaudii e Enyalius perditus) e uma serpente (Echinanthera cianopleura) encontram-se na lista de espécies provavelmente ameaçadas de São Paulo. Heterodactylus imbricatus está na lista de espécies provavelmente ameaçadas de Minas Gerais e Enyalius perditus encontra-se também na lista do Rio de Janeiro como $\mathrm{DD}$, indicando que não existem dados suficientes para determinar se a espécie está ameaçada e tampouco em que categoria de ameaça se encontra.

Encontram-se a seguir comentários sobre a biologia e distribuição das espécies de lagartos e serpentes registradas na Reserva.

Colobodactylus taunayi Amaral é um lagarto de pequeno porte, com cerca de $8 \mathrm{~cm}$ do focinho à cloaca, e cauda muito comprida. Habita a serrapilheira de áreas florestadas do planalto atlântico e baixada litorânea, estando presente inclusive em algumas ilhas da costa do estado de São Paulo. A distribuição da espécie inclui os estados de São Paulo e Santa Catarina (Vanzolini \& Ramos 1977).

Ecpleopus gaudichaudii Duméril \& Bibron é a única espécie descrita do gênero Ecpleopus. Caracteriza-se pelo porte pequeno, com cerca de $5 \mathrm{~cm}$ do focinho à cloaca, cauda comprida e membros curtos. Vive na serrapilheira de áreas florestadas alimentando-se de pequenos invertebrados. A distribuição da espécie inclui os estados do sudeste do país (Eisemberg et al. 2004).

Heterodactylus imbricatus Spix é muito similar a Colobodactylus, com o qual apresenta relações próximas de parentesco (Pellegrino et al. 2001). É um lagarto de porte pequeno (cerca de $8 \mathrm{~cm}$ ) do focinho à cloaca, com corpo alongado, quatro dedos e sem ouvido externo. Os machos apresentam a mesma coloração das fêmeas. Habita a serrapilheira de áreas florestadas montanhosas da Mata Atlântica do sudeste e sul do Brasil (Peters \& DonosoBarros 1970, M.T. Rodrigues, comun. pess.).

Enyalius perditus Jackson é um lagarto de porte médio (cerca de $10 \mathrm{~cm}$ do focinho à cloaca), de coloração bastante variável. Os machos em geral são verdes ou marrons, unicolores. As fêmeas apresentam coloração em geral marrom, com padrões complexos mais claros ao longo da linha vertebral. São predominantemente terrestres, mas sobem com freqüência em arbustos do subosque para se aquecer ao sol e dormir. Alimenta-se de artrópodes, que captura sobre o solo. Pode ser encontrado em áreas de mata do estado do Rio de Janeiro e no planalto atlântico de São Paulo. Segundo Jackson (1978), a ocorrência da espécie nos estados do Paraná e Santa Catarina é bastante provável.

Tupinambis merianae (Duméril \& Bibron) é um dos maiores lagartos do Novo Mundo (Colli et al. 1998) atingindo 
cerca de $60 \mathrm{~cm}$ do focinho à cloaca. Vive no chão em clareiras e borda de mata, muitas vezes aproximando-se de ambientes antropizados. A dieta é bastante variada e inclui matéria vegetal, moluscos, formigas, aranhas, insetos, lacraias, pequenos vertebrados e carniça (Kiefer \& Sazima 2002). A taxonomia do grupo é complexa e os limites específicos não estão bem estabelecidos. Pode ser encontrada ao sul do Rio Amazonas no Brasil, em todo o território nacional e também na Argentina, Paraguai e Uruguai (Colli et al. 1998).

Echinantera cyanopleura (Cope) é uma espécie de serpente de pequeno porte (cerca de $60 \mathrm{~cm}$ ) e coloração geral do corpo marrom com faixas dorsolaterais mais claras. A lateral e a base da cabeça são amarelas e a cauda é longa. Apresenta hábito terrestre e pode estar ativa durante o dia e à noite, mas é raramente avistada. A dentição é áglifa e a alimentação inclui anuros e pequenos lagartos (Marques et al. 2001). Apresenta ampla distribuição na Mata Atlântica do sudeste do Brasil (Sazima 2001, Freitas 2003)

Micrurus coralinus (Merrem) é uma espécie peçonhenta muito característica por sua coloração que alterna anéis de cor negra, branca e vermelha. Pode chegar a $95 \mathrm{~cm}$ de comprimento, a cabeça é arredondada, os olhos muito pequenos e a cauda é curta. É diurna e semifossorial, mas freqüentemente encontrada. A dentição é proteróglifa e a espécie alimenta-se de outras serpentes e vertebrados alongados (Marques et al. 2001). Pode ser encontrada em áreas de Mata Atlântica do estado de Santa Catarina ao sul da Bahia (Melgarajo 2003).

Bothrops jararaca (Wied) é uma espécie peçonhenta de porte médio, atingindo cerca de $1 \mathrm{~m}$ de comprimento. Caracteriza-se pela coloração clara à escura com padrão triangulado complexo no dorso. Possui hábito terrestre e semi-arborícola, encontrando-se ativa durante o dia e à noite. É bastante comum, encontrada em áreas de mata, mas também penetra plantações, próximas a ambientes florestais. A dentição é solenóglifa, os jovens alimentam-se de anuros e os adultos de roedores e ocasionalmente aves (Sazima \& Haddad 1992, Marques et al. 2001). Pode ser encontrada no sul e sudeste do Brasil até o sul da Bahia e também no Paraguai e Argentina (Campbell \& Lamar 2004).

Dentre os répteis amostrados pelas armadilhas de interceptação e queda estão três espécies de lagartos e duas espécies de serpentes (Tabela 2). O método de amostragem empregado nesse estudo não é ideal para amostragem de cobras e de lagartos arborícolas, e a riqueza deste grupo está certamente subestimada. Das quatro espécies de lagartos amostrados na Reserva, Ecpleopus gaudichaudii e Enyalius perditus corresponderam a $54 \%$ e $43 \%$ respectivamente do total amostrado e foram encontrados em todas as áreas (Tabela 2). Colobodactylus taunayi e Heterodactylus imbricatus, que juntos correspondem a 3\% dos 111 lagartos amostrados, parecem ser realmente pouco comuns na Reserva, uma vez que são espécies bem amostradas pelas armadilhas de interceptação e queda (observação pessoal).
A fauna de lagartos e serpentes da Mata Atlântica é estimada em torno de 50 espécies de lagartos e 80 espécies de serpentes em todo o bioma (Sazima 2001). O número de espécies registradas na Reserva Florestal de Morro Grande até o momento é muito inferior ao que deve ser a diversidade real da área, principalmente no que se refere aos lagartos arborícolas e às serpentes. Em relação à quantidade amostrada de lagartos, a Reserva Florestal de Morro Grande apresenta riqueza igual à registrada na Serra do Japi e na Fazenda Intervales (5spp), e menor do que aquela registrada na Estação Ecológica Juréia-Itatins (7spp) (Sazima \& Haddad 1992, Sazima 2001, Marques \& Sazima 2004). Mas na Reserva predominam espécies de serrapilheira e nas outras duas localidades, espécies arborícolas.

\section{Considerações finais}

Os resultados acima indicam ainda uma carência de dados no que se refere a levantamentos e padronização de métodos de amostragem que permitam comparações detalhadas entre localidades em áreas de Mata Atlântica. A utilização de métodos diferentes visivelmente provoca desvios nas listas de espécies que dificultam análises considerando riqueza e abundância. As armadilhas de queda parecem ser um método promissor, que permite padronização suficiente para análises desse tipo, pelo menos em se tratando de espécies de hábito terrestre e fossorial. Muitas espécies de grupos com essas características têm tido sua distribuição ampliada, seu status populacional modificado, ou ainda, têm sido descobertas a partir desse método (Rodrigues et al. 2002a,b, Verdade \& Rodrigues 2003, Dixo 2004, Dixo \& Verdade 2004).

Trabalhos de esforço pontual, que visem conhecer a composição e distribuição da fauna localmente, considerando variáveis ambientais e efeitos decorrentes da fragmentação de hábitat são extremamente importantes no atual contexto. Sabemos que a fragmentação ambiental pode, a longo prazo, provocar declínios populacionais e extinções locais, além disso, o desmatamento abre espaço para espécies invasoras, que em diferentes graus podem competir com as espécies nativas.

As atividades agropecuárias que se estabelecem nessas áreas desmatadas também trazem ameaças pouco conhecidas. Em alguns casos, espécies de uso comercial, como Rana catesbeiana invadem o ambiente, oriundas de ranários. Essa é uma espécie de grande porte que compete por recursos e preda as espécies nativas. Atualmente, a presença de Rana catesbeiana no sudeste e sul do Brasil tem gerado esforços para que a ampliação da distribuição da espécie seja contida. Em algumas áreas no interior do estado de São Paulo Rana catesbeiana parece não conseguir estabelecer populações em ambientes naturais (J. Jim, comunicação pessoal). Estabelecer os fatores que limitam a distribuição dessa espécie seria uma importante 
ferramenta para a análise de processos de licenciamento e implantação de novos ranários.

A proximidade a áreas agrícolas também expõem as populações a produtos químicos utilizados como adubos, pesticidas e inseticidas, cujo processo de degradação e efeitos sobre a fauna associada ao solo e à água são pouco conhecidos. Os anfíbios particularmente, são muito susceptíveis a esses contaminantes por utilizarem na reprodução os ambientes aquáticos que recebem as águas provenientes das lavouras. Estudos realizados no hemisfério norte indicam que a degradação de químicos em ambiente natural difere daquela em condições de laboratório, e que, em alguns casos, o composto secundário decorrente da degradação é tão ou mais prejudicial que o produto inicial (Hayes et al. 2002). Sabe-se também, que quanto maior o número de compostos interagindo, maior o efeito degradante sobre a fauna. Em alguns casos, quantidades mínimas dissolvidas podem provocar problemas de desenvolvimento em anfíbios relacionados a feminilização dos machos (Hayes et al. 2002).

O conhecimento atual sobre a biologia, distribuição e conservação da herpetofauna brasileira ainda é muito restrito. Existem vazios amostrais, inclusive dentro de biomas considerados mundialmente como prioritários em decorrência do elevado grau de endemismos e pressão antrópica a que estão expostos, como é o caso da Mata Atlântica (Myers et al. 2000). Esforços imediatos voltados à preservação das poucas áreas de mata restantes no Domínio (Ab’Saber 1970) são necessários, dada a velocidade de degradação dos remanescentes florestais. Nesse sentido, inventários de fauna e monitoramentos podem suprir lacunas importantes sobre a biologia dessas espécies e somente esse tipo de conhecimento pode formar a base sólida necessária à elaboração de medidas mitigatórias e conservacionistas eficientes.

\section{Agradecimentos}

A realização desse trabalho em suas diversas fases dependeu da ajuda de vários colegas e profissionais a quem sinceramente agradecemos. Jean Paul Metzger, pelo apoio e coordenação do projeto temático “Conservação da Biodiversidade em Paisagens Fragmentadas no Planalto Atlântico de São Paulo” (BIOTA/FAPESP processo 99/ 05123-4), Hussam Zaher por permitir o acesso à coleção do Museu de Zoologia da Universidade de São Paulo, Carolina Castro-Mello, por facilitar procedimentos relacionados à coleção, Miguel T. Rodrigues pela identificação dos lagartos, Claude Gascon e Célio F. B. Haddad pelos comentários que enriqueceram esse manuscrito. Ao Henning Steinicke, José Mario B. Ghellere, Marcelo Awade, Maria Cristina J. Peruzin, Ricardo Braga Neto e Sergio Marques de Sousa pela inestimável ajuda no campo. À Fundação de Amparo a Pesquisa do Estado de São Paulo (FAPESP) e à Fundação O Boticário de Proteção à Natureza pelo financiamento. Ao
José Roberto Nali, encarregado de sistemas de saneamento da SABEP por permitir e facilitar a realização do presente estudo na Reserva Florestal de Morro Grande e ao Instituto Brasileiro do Meio Ambiente e Recursos Naturais Renováveis (IBAMA) por permitir a captura e coleta da herpetofauna na região.

\section{Referências bibliográficas}

AB'SABER, A.N. 1970. Províncias geológicas e domínios morfoclimáticos no Brasil. Geomorfologia 20:1-25.

ABRAVAYA, J.P. \& JACKSON, J.F. 1978. Reproduction in Macrogenioglottus alipioi Carvalho (Anura, Leptodactylidae). Nat. Hist. Mus. Los. Ang. Cty. Contrib. Sci. 298:1-9.

BALDISSERA, S.A.Jr., CARAMASCHI, U. \& HADDAD, C.S.D. 2004. Review of the Bufo crucifer species group with the description of two new related species (Amphibia: Anura: Bufonidae). Arq. Mus. Nac. Rio J. 62(3):255-282.

BASTOS, R.P. \& POMBAL JR., J.P. 1995. New species of Crossodactylus (Anura, Leptodactylidae) from the Atlantic rainforest of southeastern Brazil. Copeia 1995(2):436-439.

BASTOS, R.P. \& POMBAL JR., J.P. 2001. Geographic distribution: Eleutherodactylus juipoca. Herpetol. Rev. 32(2):113.

BERGALLO, H.G., ROCHA, C.F.D.,ALVES, M.A.S. \& SLUYS, M.V. 2000. A fauna ameaçada de extinção do estado do Rio de Janeiro. Editora da Universidade do Estado do Rio de Janeiro, Rio de Janeiro.

BERTOLUCI, J.A. 1997. Fenologia e seleção de habitat em girinos da Mata Atlântica em Boracéia, São Paulo (Amphibia, Anura). Tese de doutorado, Instituto de Biociências, Universidade de São Paulo, São Paulo.

BERTOLUCI, J.A. 2001. Anfíbios anuros. In Intervales/ Fundação para a conservação e produção florestal do estado de São Paulo (C. Leonel, ed.). São Paulo, A Fundação, p.159-168.

CAMPBELL, J.A. \& LAMAR, W.W. 2004. The Venomous Reptiles of the Western Hemisphere. Volume II. Cornell University Press, Ithaca.

CARDOSO, A.J. \& HADDAD, C.F.B. 1985. Nova espécie de Physalaemus do grupo signiferus (Amphibia, Anura, Leptodactylidae) Rev. Bras. Biol. 45:33-37.

CECHIN, S.Z. \& MARTINS, M. 2000. Eficiência de armadilhas de queda (pitfall traps) em amostragens de anfíbios e répteis no Brasil. Rev. Bras. Zool. 17:729-740.

COCHRAN, D.M. 1955. Frogs of southeastern Brazil. US. National Museum Bulletin 206:1-411.

COLLI, G.R., PERES, A.K. \& CUNHA, H.J. 1998. Anew species of Tupinambis (Squamata: Teiidae) from central Brazil, with an analysis of morphological and genetic variation in the genus. Herpetologica 54(4):477-492. 
CORN, P.S. 1994. Standard techniques for inventory and monitoring - Straight-line drift fences and pitfall traps. In Measuring and monitoring biological diversity. Standard methods for amphibians (W.R. Heyer, M.A. Donnelly, R.W. Mcdiarmid, L.C. Hayek \& M.S. Foster, eds.). Smithsonian Institution Press, Washington, p.118-124.

CRUZ, C.A.G., CARAMASCHI, U. \& IZECKSOHN, E. 1997. The genus Chiasmocleis Mehely, 1904 (ANURA, MICROHYLIDAE) in the Atlantic Forest of Brazil, with description of three new species. Alytes 15(2):49-71.

DAVIDSON, C., SHAFFER, H.B. \& JENNINGS, M.R. 2001. Declines of the California red-legged frog: climate, UV-B, habitat, and pesticides hypotheses. Ecol. Appl. 11:464-479.

DIXO, M. 2004. Rediscovery of Hyophryne histrio (Anura, Microhylidae) in Atlantic Forest remnants of Bahia, northeastern Brazil. Phyllomedusa 3(1):77-79.

DIXO, M. \& VERDADE, V.K. 2004. Geographic distribution. Cycloramphus migueli (Miguel's Button Frog). Herpetol. Rev. 35(3):280.

DONNELLY, M.A. \& GUYER, C. 1994. Estimating population size. In Measuring and monitoring biological diversity. Standard methods for amphibians (W.R. Heyer, M.A. Donnelly, R.W. Mcdiarmid, L.C. Hayek \& M.S. Foster, eds.). Smithsonian Institution Press, Washington, p.183-200.

DUELLMAN, W.E. \& GRAY, P. 1983. Developmental biology and systematics of the egg-brooding hylid frogs, genera Flectonotus and Fritziana. Herpetologica 39(4):333-359.

EISEMBERG, C.C., CASSIMIRO, J. \& BERTOLUCI, J. 2004. Notes on the diet of the rare gymnophthalmid lizard Ecpleopus gaudichaudii from southeastern Brazil. Herpetol. Rev. 35(4):336-337.

ESTRADA, A.R. \& HEDGES, S.B. 1996. At the lower limit in tetrapods: a new diminutive frog from Cuba (Leptodactylidae: Eleutherodactylus). Copeia 1996(4):852-859.

FAIVOVICH, J., HADDAD, C.F.B., GARCIA, P.C.A., FROST, D.R., CAMPBELL, J.A. \& WHEELER, W.C. 2005. Systematic review of the frog family Hylidae, with special reference to Hylinae: phylogenetic analysis and taxonomic revision. Bull. Am. Mus. Nat. Hist. 294: 1-294.

FROST, D.R. 2004. Amphibian Species of the World: an Online Reference. Version 3.0 Electronic Database accessible at http://research.amnh.org/herpetology/amphibia/index.html. American Museum of Natural History, New York, USA. (último acesso: 15 de setembro de 2004).

GIARETTA, A.A. \& SAWAYA, R.J. 1998. Second species of Psyllophryne (Anura: Brachycephalidae). Copeia 1998(4):985-987.

GIARETTA, AA., FACURE, K.G., SAWAYA, R.J., MEYER, J.H.D.M. \& CHEMIN, N. 1999. Diversity and abundance of litter frogs in a montane forest of Southeastern Brazil: seasonal and altitudinal changes. Biotropica 31:669-674.
GUIX, J.C., MONTORI, A., LLORENTE, G.A., CARRETERO, M.A. \& SANTOS, X. 1998. Natural history and conservation of Bufonids in four atlantic rainforest areas of southeastern Brazil. Herpetol. Nat. Hist. 6(1):1-12.

HADDAD, C.F.B. \& HÖDL, W. 1997. New reproductive mode in anurans: bubble nest in Chiasmocleis leucosticta (Microhylidae). Copeia 1997:585-588.

HADDAD, C.F.B. \& SAZIMA, I. 1992. Anfíbios anuros da Serra do Japi. In História Natural da Serra do Japi. Ecologia e preservação de uma área florestal no sudeste do Brasil (P. Morellato, org.). Editora da UNICAMP, Campinas, p.188-211.

HADDAD, C.F.B. 1998. Biodiversidade dos anfíbios no estado de São Paulo. In Biodiversidade do estado de São Paulo, Brasil. Síntese do conhecimento ao final do século XX. 6. Vertebrados. (R. Castro, ed.). FAPESP, São Paulo, p.17-26.

HAYES, T.B., COLLINS, A., LEE, M., MENDOZA, M., NORIEGA, N., STUART, A.A. \& VONK, A. 2002. Hermaphroditic, demasculinized frogs after exposure to the herbicide atrazine at low ecologically relevant doses. PNAS 99(8):5476-5480.

HEYER, W.R. 1973. Systematic of the marmoratus group of the frog genus Leptodactylus (Amphibia, Leptodactylidae). Nat. Hist. Mus. Los. Ang. Cty. Contrib. Sci. 251:1-50.

HEYER, W.R. 1980. The calls and taxonomic positions of Hyla giesleri and Ololygon opalina (AMPHIBIA:ANUR:HYLIDAE). Proc. Biol. Wash. 93(3):655-611.

HEYER, W.R. 1984. Variation, systematics, and Zoogeography of Eleutherodactylus guentheri and closely related species (Amphibia, Anura, Leptodactylidae). Smith. Contr..Zool. 402:1-42.

HEYER, W.R., RAND, A.S., CRUZ, C.A.G. \& PEIXOTO, O.L. 1988. Decimations, extinctions, and colonizations of frog populations in southeast Brazil and their evolutionary implications. Biotropica 20:230-235.

HEYER, W.R., RAND, A.S., CRUZ, C.A.G., PEIXOTO, O.L. \& NELSON, C.E. 1990. Frogs of Boracéia. Arq. Zool. (São Paulo) 31:231-410.

IBAMA 2003. Lista nacional das espécies da fauna brasileira ameaçadas de extinção. Electronic Database accessible at http://www.mma.gov.br/port/sbf/fauna/index.cfm (último acesso: 18 de setembro de 2004)

IUCN, CONSERVATION INTERNATIONAL \& NATURE SERVE. 2004. Global Amphibian Assessment.http:// www.globalamphibians.org. (último acesso: 18 de setembro de 2004)

IZECKSOHN, E. 1971. Variação no padrão vertebral de Dendrophryniscus brevipollicatus Espada. Arq. Mus. Nac. Rio J. LIV:129-136. 
IZECKSOHN, E. \& CARVALHO-E-SILVA, S.P. 2001. Anfíbios do município do Rio de Janeiro. Editora UFRJ, Rio de Janeiro.

JACKSON, J.F. 1978. Differentiation in the genera Enyalius and Strobilurus (Iguanidae): implications for Pleistocene climatic changes in eastern Brazil. Arq. Zool. (São Paulo) 30:1-79.

KAPLAN, M. 2002. Histology of the anteroventral part of the breast-shoulder apparatus of Brachycephalus ephippium (Brachycephalidae) with comments on the validity of the genus Psyllophryne (Brachycephalidae). Amphibia-Reptilia 23:225-227.

KIEFER, M.C. \& SAZIMA, I. 2002. Diet of juvenile tegu lizard Tupinambis merianae (Teiidae) in southeastern Brazil. Amphibia-Reptilia 23:105-108.

KOVACH, W.L. 1999. MVSP. A Multivariate Statistical Package for windows, ver. 3.1. Kovach Computing services, Pentraeth, Wales.

LEITÃO FILHO, H.F. 1982. Aspectos taxonômicos das florestas do estado de São Paulo. Silvic. São Paulo 16A:197-206.

LOPES, M.I.M.S. 2001. Fluxo de água, balanço químico e alterações no solo da floresta atlântica atingida pela poluição aérea de Cubatão, São Paulo, Brasil. Tese de doutorado, Universidade de São Paulo, São Paulo.

LUTZ, B. 1973. Brazilian species of Hyla. University of Chicago Press, Austin.

LYNN, W.G. \& LUTZ, B. 1946. The development of Eleutherodactylus guentheri Stdnr. 1864. Bol. Mus. Nac. Rio de J. Zool. 71:1-21.

MACHADO, A.B.M., FONSECA, G.A.B., MACHADO, R.B., AGUIAR, L.M.S. \& LINS. L.V. 1998. Livro vermelho das espécies ameaçadas de extinção da fauna de Minas Gerais. Fundação Biodiversitas, Belo Horizonte Electronic Database accessible at http:// www.biodiversitas.org.br/f_ameaca/index_lista.htm (último acesso: 18 de setembro de 2004).

MAGURRAN, A.E. 1988. Ecological Diversity and its measurement. Princenton University Press, Princenton.

MARQUES, O.A.V., ABE, A.S. \& MARTINS, M. 1998. Estudo diagnóstico da diversidade de répteis do estado de São Paulo. In Biodiversidade do estado de São Paulo, Brasil. Síntese do conhecimento ao final do século XX. 6. Vertebrados. (R. Castro, ed.). FAPESP, São Paulo,p.29-38.

MARQUES, O.A.V., ETEROVIC, A. \& SAZIMA, I. 2001. Serpentes da Mata Atlântica. Guia ilustrado para a Serra do Mar. Holos Editora Ltda, Ribeirão Preto.

MARQUES, O.A.V. \& SAZIMA, I. 2004. História natural dos répteis da estação ecológica Juréia-Itatins. In Estação Juréia-Itatins: ambiente físico, flora e fauna (O.A.V. Marques \& V. Duleba, eds). Holos Editora, Ribeirão Preto, p.257-277.
McCUNE, B., MEFFORD, M. J. 1997. Multivariate analysis of ecological data. Version 3.11. MjM Software, Gleneden beach, Oregon.

MELGARAJO, A.R. 2003. Serpentes peçonhentas do Brasil. In Animais Peçonhentos no Brasil. Biologia, clínica e terapêutica dos acidentes. (J.L.C. Cardoso, F.O.S. França, F.H. Wen, C.M.S. Málaque \& V. Haddad Jr., eds.). Editora Sarvier, São Paulo, p.33-61.

MIKICH, S.B. \& BÉRNILS, R.S. 2004. Livro vermelho da fauna ameaçada no estado do Paraná. Instituto ambiental do Paraná, Curitiba, CD-Rom.

MIRANDA-RIBEIRO, A. 1922. Basanitia lactea. Um novo batrachio das collecções do Museu Paulista. Rev. Mus. Paulista 13:851-853.

MYERS, N., MITTERMEIER, R.A., MITTERMEIER, C.G., FONSECA, G.A.B. \& KENT, J. 2000. Biodiversity hotspots for conservation priorities. Nature 403:853-858.

OLIVEIRA, F. B. \& NAVAS, C.A. 2004. Plant selection and seasonal patterns of vocal activity in two populations of the bromeligen treefrog Scinax perpusillus (Anura: Hylidae). J. Herpetol. 38(3):331-339.

PELLEGRINO K.C.M., RODRIGUES M.T., YONENAGAYASSUDA, Y., SITES, J.W.JR. 2001. A molecular perspective on the evolution of South American microteiid lizards (Squamata, Gymnophthalmidae), and a new classification for the family. Biol. J. Linn. Soc. 74:317-340.

PETERS, J.A. \& DONOSO-BARROS, R. 1970. Catalogue of the Neotropical Squamata. Part II. Lizards and amphisbaenians. Smithsonian Institution Press, Washington D.C.

PEIXOTO, O.L. 1987. Caracterização do grupo perpusilla e reavaliação da posição taxonômica de Ololygon perpusilla perpusilla e Ololygon perpusilla visignata (Amphibia, Anura, Hylidae). Arq. Univ. Fed. Rur. Rio J. 10(1-2):37-49.

POMBAL JR., J.P. 1995. Biologia reprodutiva de anuros (Amphibia) associados a uma poça permanente na Serra de Paranapiacaba, Sudeste do Brasil. Tese de doutorado, Universidade Estadual Paulista Júlio de Mesquita Filho, Rio Claro.

POMBAL JR, J.P. \& GORDO, M. 2004. Anfíbios Anuros da Juréia. In Estação Ecológica Juréia-Itatins. Ambiente físico, Flora e Fauna (O.A.V. Marques \& V. Duleba, eds). Holos Editora, Ribeirão Preto, p.243-256.

POUGH, F.H., ANDREWS, R.M., CADLE, J.E., CRUMP, M.L., SAVITZKY, A.H. \& WELLS, K.D. 1998. Herpetology. Prentice Hall, Upper Saddle River, New Jersey.

RODRIGUES, M.T., DIXO, M. \& ACCACIO, G.M. 2002. A large sample of Leposoma (Squamata, Gymnophthalmidae) from the Atlantic forests of Bahia, the status of Leposoma annectans Ruibal, 1952, and notes on conservation. Pap. Avulsos Zool. (São Paulo) 42:103-117. 
RODRIGUES, M.T., DIXO, M., PAVAN, D. \& VERDADE, V.K. 2002. A new species of Leposoma (Squamata, Gymnophthalmidae) from the remnant Atlantic forests of the state of Bahia, Brazil. Pap. Avulsos Zool. (São Paulo) 42:335-350.

SÃO PAULO (estado). 1998. Secretaria do Estado do meio Ambiente. Fauna Ameaçada no estado de São Paulo. SMA/CED, série PROBIO/SP, São Paulo.

SAZIMA, I. \& CARDOSO, A.J. 1978. Uma espécie nova de Eleutherodactylus do sudeste brasileiro (AMPHIBIA, ANURA, LEPTODACTYLIDAE). Rev. Bras. Biol. 38(4):921-925.

SAZIMA, I. \& HADDAD, C.F.B. 1992. Répteis da Serra do Japi: notas sobre história natural. In História Natural da Serra do Japi. Ecologia e preservação de uma área florestal no sudeste do Brasil. (P. Morellato, org.). Editora da UNICAMP. p.212-235.

SAZIMA, I. 2001. Répteis. In Intervales/ Fundação para a conservação e produção florestal do estado de São Paulo (C. Leonel, ed.). A Fundação, São Paulo, p.148-158.

SNEATH P.H.A. \& SOKAL, R.R. 1973. Numerical Taxonomy. Freeman, San Francisco.

UETZ, P., ETZOLD, T. \& CHENNA, R. 1995. The EMBL Reptile Database. Electronic Database accessible at http:/ /www.embl-heidelberg.de/ uetz/LivingReptiles.html (último acesso: 18 de setembro de 2004).

VANZOLINI, P.E. \& RAMOS, A.M.M. 1977. Anew species of Colobodactylus, with notes on the distribution of a group of stranded microteiid lizards (sauria, teiidae). Pap. Avulsos Zool. (São Paulo) 31:19-47.

VAZ-FERREIRA, R., OLMOS, A. \& STAGI, A. 1999. Canibalismo de los machos de Leptodactylus ocellatus "Rana criolla” (Amphibia, Anura) sobre larvas gregarias protegidas por la madre. Mus. Nac. Hist. Nat. Mont. Publ. Extra 50:116.

VERDADE, V.K. \& RODRIGUES, M.T. 2003. A new species of Cycloramphus (Anura, Leptodactylidae) from the Atlantic Forest, Brazil. Herpetologica 59(4):513-518.

VERDADE, V.K., RODRIGUES, M.T. \& PAVAN, D. (no prelo). Anfíbios Anuros da Reserva Biológica de Paranapiacaba e entorno. In A Reserva Biológica de Paranapiacaba: a Estação Biológica do Alto da Serra (M.I.M.S Lopes, M. Kirizawa \& M.M.R.F Melo, orgs.). Editora Secretaria do Meio Ambiente do Estado de São Paulo, São Paulo.

VIZOTTO, L.D. 1984. Ranicultura. Cienc. Cult. 36(1):42-45.

WEYGOLDT, P. 1989. Changes in the composition of mountain stream frog communities in the Atlantic mountains of Brazil: frogs as indicators of environmental deteriorations? Stud. Neotrop. Fauna Environ. 243(4):249-255.

WOLDA, H. 1981. Similarity indices, sample size and diversity. Oecologia 50:296-302.
YOUNG B.E., LIPS, K.R., REASER, J.K., IBANEZ, R., SALAS, A.W., CEDENO, J.R., COLOMA, L.A., RON, S., LA MARCA, E., MEYER, J.R., MUNOZ, A., BOLANOS, F., CHAVES, G. \& ROMO, D. 2001. Population declines and priorities for amphibian conservation in Latin America. Conserv. Biol. 15:1213-1223.

ZIMMERMAN, B.L. \& BIERREGAARD, R.O. 1985. Relevance of the equilibrium theory of island biogeography and species-area relations to conservation with a case from Amazonia. J. Biogeogr. 13: 133-143.

Título: Herpetofauna de serrapilheira da Reserva Florestal de Morro Grande, Cotia (SP).

Autores: Dixo, M. \& Verdade, V.K.

Biota Neotropica, Vol. 6 ( número 2): 2006

http://www.biotaneotropica.org.br/v6n2/pt/ abstract?article+bn00806022006

Recebido em 11/1/2004 - Versão reformulada recebida em 22/1/2005 - Publicado em 01/05/2006

ISSN 1676-0603 


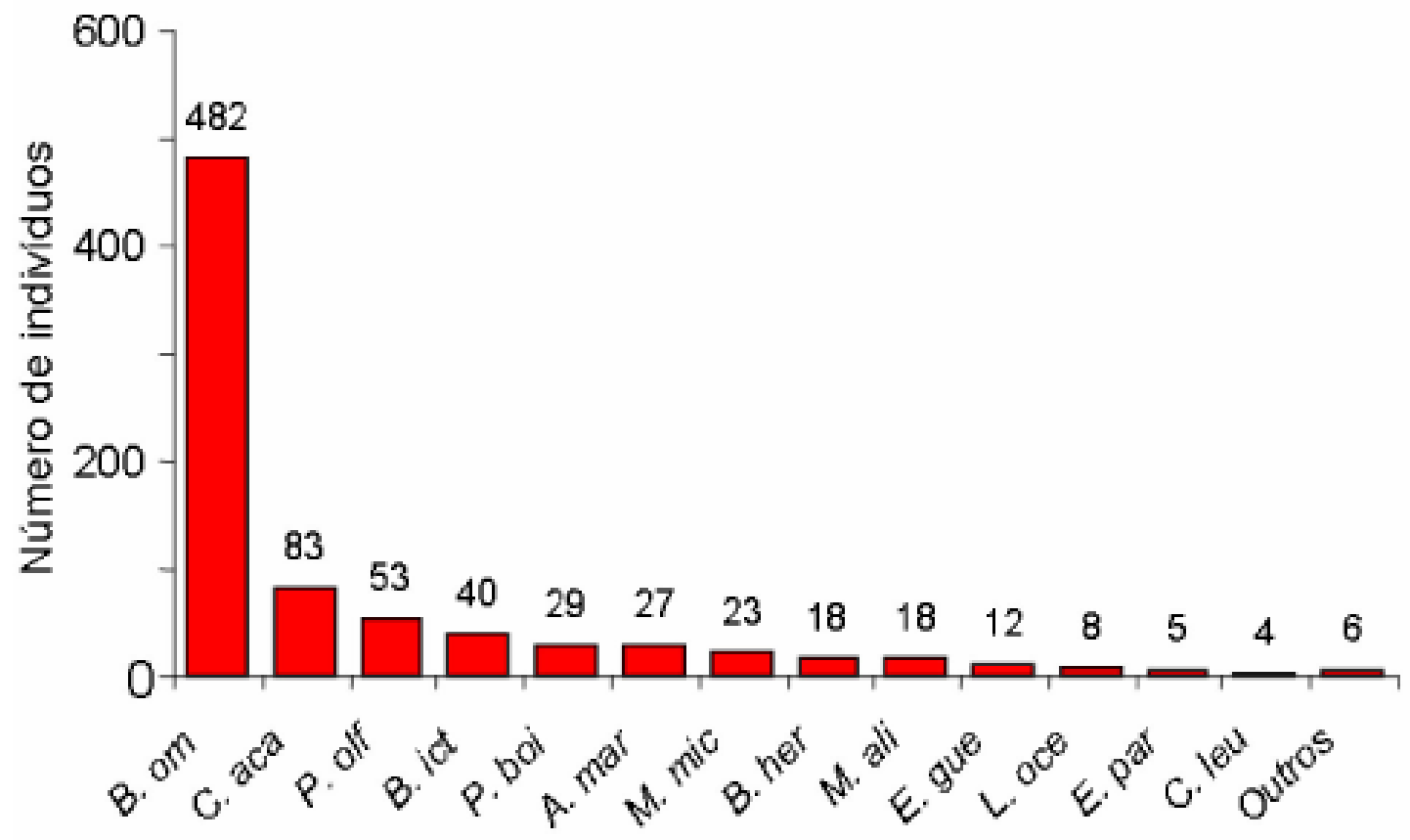

Figura 1. Distribuição de abundância das espécies de anuros amostrados pelas armadilhas de interceptação e queda na Reserva Florestal de Morro Grande, Cotia (SP). B.orn, Bufo ornatus; C.aca, Cycloramphus acangatan; P.olf, Physalaemus olfersii; B.ict, Bufo ictericus; P.boi, Proceratophrys boiei; A.mar, Adenomera marmorata; M.mic, Myersiella microps; Bher, Brachycephalus hermogenesi; M.ali, Macrogenioglottus alipioi; E.gue, Eleutherodactylus guentheri; L.oce, Leptodactylus ocellatus; E.par, Eleutherodactylus parvus; C.leu, Chiamoscleis leucosticta; Outros= Eleutherodactylus juipoca $(n=1)$; Dendrophryniscus brevipollicatus $(n=2)$; Physalaemus cuvieri $(n=1) e$ Rana catesbeiana $(n=1)$ B.eph, Brachycephalus ephippium $(n=1)$.

Figure 1. Abundance distribution of the anurans species sampled by pitfall traps at Reserva Florestal de Morro Grande, Cotia (SP). B.orn, Bufo ornatus; C.aca, Cycloramphus acangatan; P.olf, Physalaemus olfersii; B.ict, Bufo ictericus; P.boi, Proceratophrys boiei; A.mar, Adenomera marmorata; M.mic, Myersiella microps; Bher, Brachycephalus hermogenesi; M.ali, Macrogenioglottus alipioi; E.gue, Eleutherodactylus guentheri; L.oce, Leptodactylus ocellatus; E.par, Eleutherodactylus parvus; C.leu, Chiamoscleis leucosticta; Other= Eleutherodactylus juipoca $(n=1)$; Dendrophryniscus brevipollicatus $(n=2)$; Physalaemus cuvieri $(n=1)$; Rana catesbeiana $(n=1)$; and B.eph, Brachycephalus ephippium $(n=1)$.

http://www.biotaneotropica.org.br 


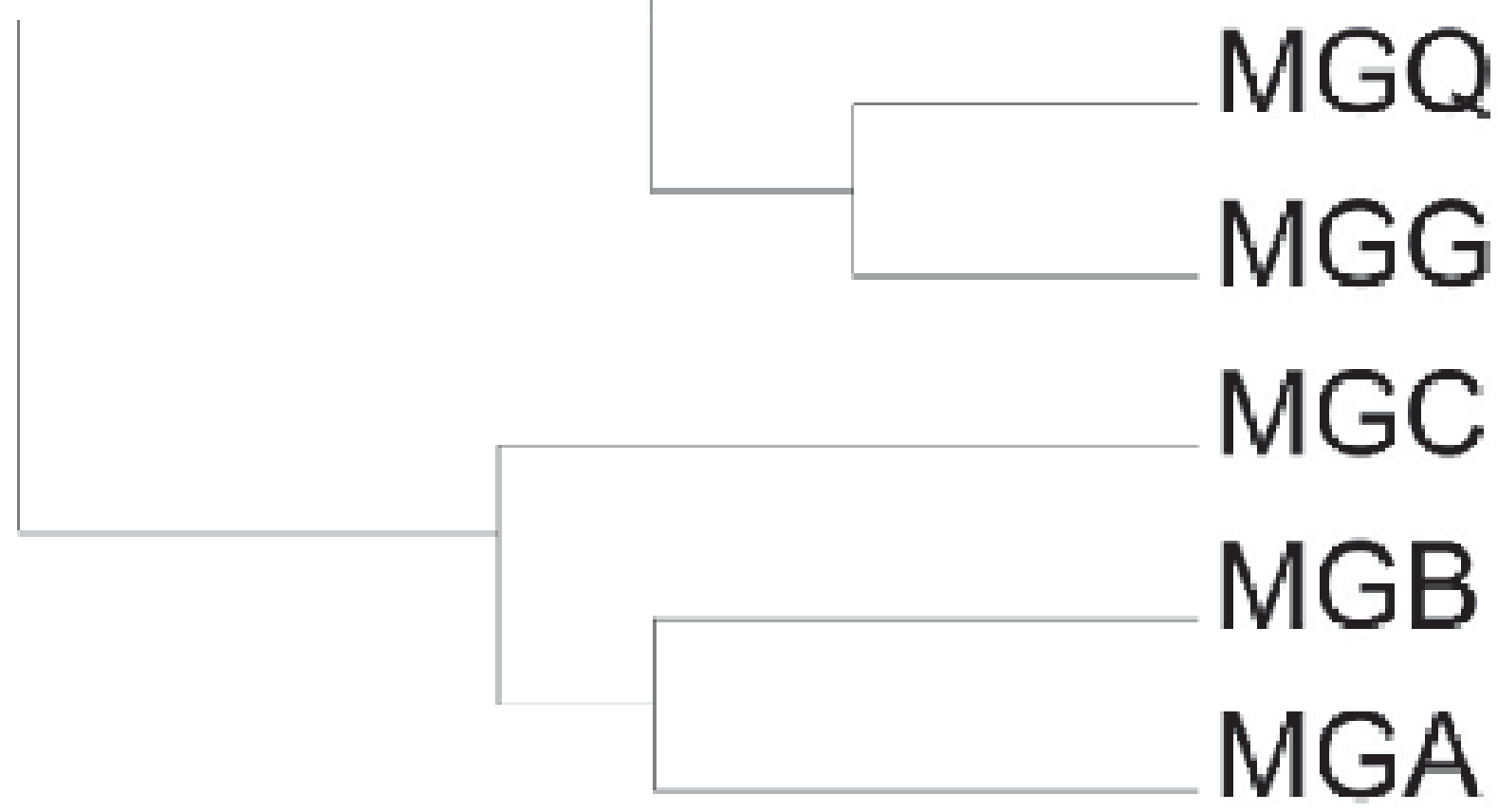

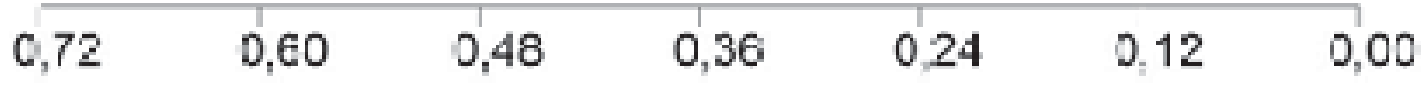

Bray Curtis

Figura 2. Dendrograma da análise de agrupamento resultante da abundância de espécies de anuros de serrapilheira das seis áreas amostradas na Reserva Florestal de Morro Grande. Índice de Bray-Curtis e método de agrupamento "WPGMA" (média de agrupamento com peso; ver detalhe no texto). As abreviaturas correspondem as áreas amostradas na Reserva do Morro Grande (MG): A, B, C, Grilos (G), Quilombo (Q) e Torres (T).

Figure 2. Cluster analysis dendrogram of the leaf litter anuran species abundance from six areas sampled at Reserva Florestal de Morro Grande. Bray-Curtis indices and cluster analysis "WPGMA" (weighting considered in cluster average; see text for details). The abbreviations stands for the areas sampled at the Reserva do Morro Grande (MG): A, B, C, Grilos (G), Quilombo (Q) and Torres (T). 


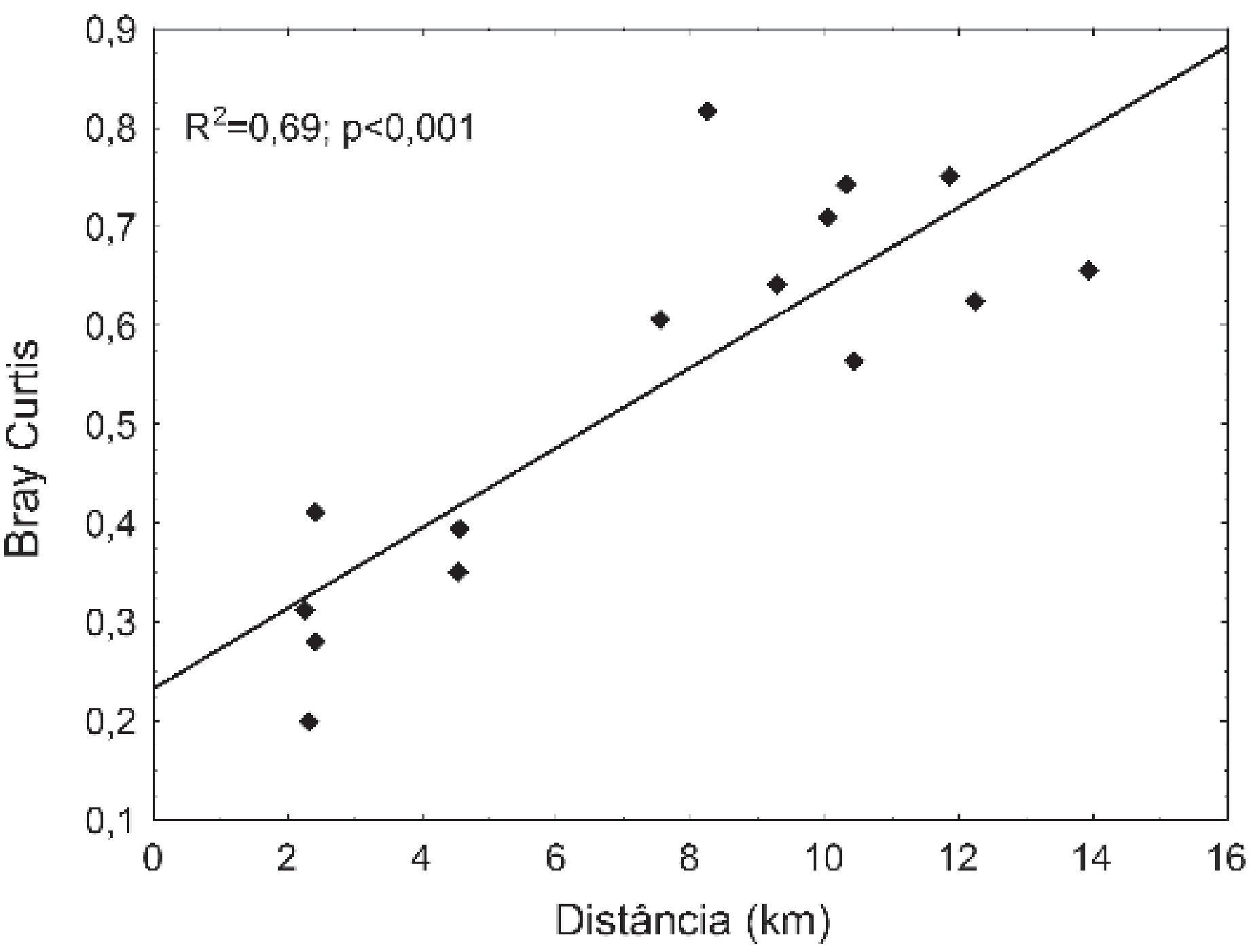

Figura 3. Variação da dissimilaridade da comunidade de anuros de serrapilheira (Bray-Curtis) nas localidades amostradas na Reserva Florestal de Morro Grande em relação à distância geográfica das mesmas.

Figure 3. Dissimilarity variation of leaf litter anuran community (Bray-Curtis) of the six localities sampled at Reserva Florestal de Morro Grande related to the geographic distance among them.

http://www.biotaneotropica.org.br 
A
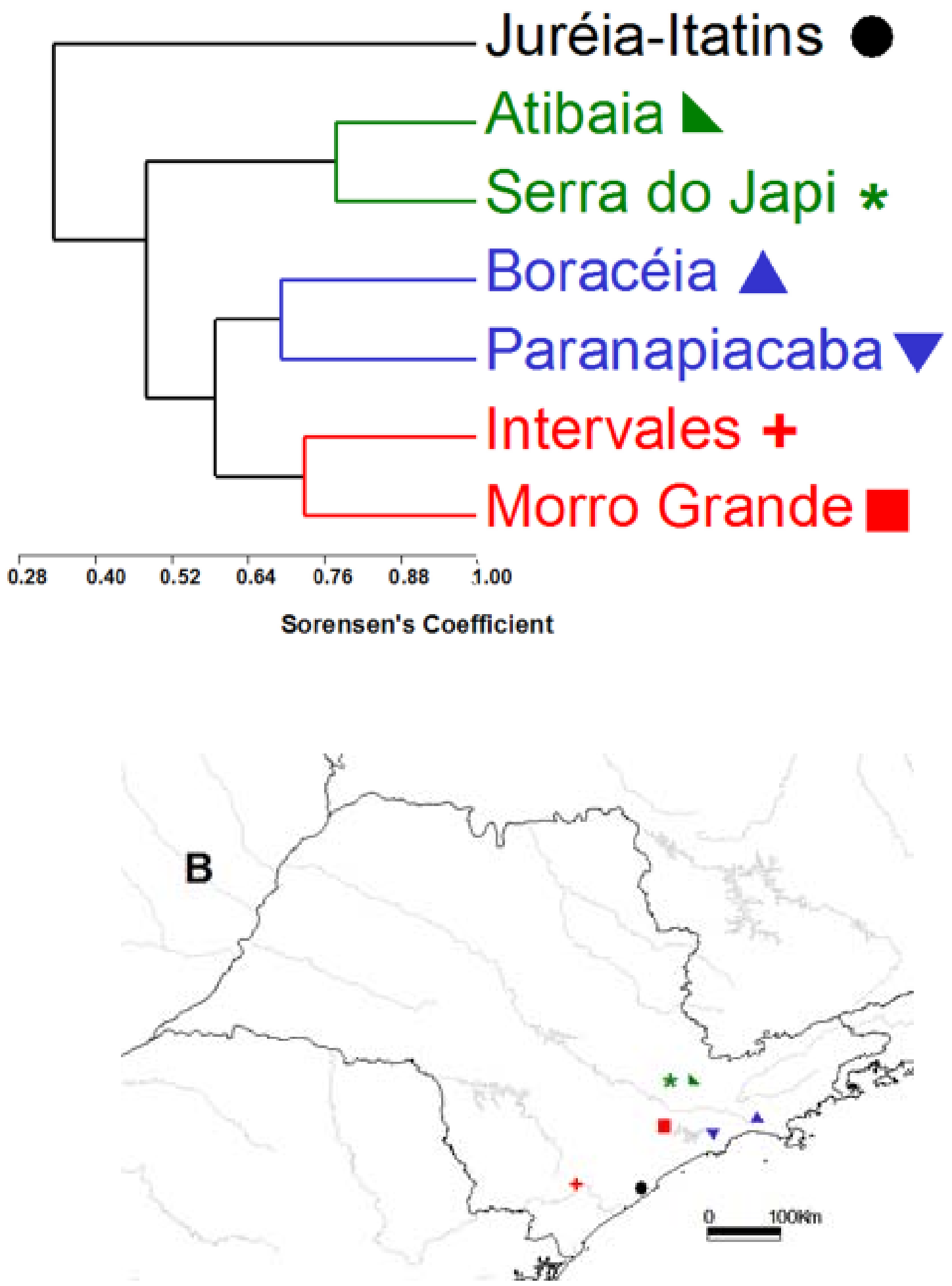

Figura 4. A. Dendrograma da análise de agrupamento resultante da presença de espécies de anuros de serrapilheira de sete taxocenoses de áreas de Mata Atlântica no estado de São Paulo. Índice de Sorensen e método de agrupamento "WPGMA” (média de agrupamento com peso; ver detalhe no texto). B. Mapa das localidades no estado de São Paulo.

Figure 4. A. Cluster analysis dendrogram of leaf litter anurans presence in seven assemblages from Atlantic Forest areas of the State of São Paulo. Sorensen indices and cluster analysis "WPGMA" (weighting considered in cluster average; see text for details). B. Locality map, State of São Paulo.

http://www.biotaneotropica.org.br 
Tabela 1. Abundância das espécies de anuros, Abundância total, Riqueza e Equitatividade (Shannon) da taxocenose de anuros amostrada nas seis áreas da Reserva Biológica de Morro Grande, Cotia, SP, Brasil. Com asterisco espécies amostradas fortuitamente fora da época do estudo. As abreviaturas correspondem as áreas amostradas na Reserva do Morro Grande (MG): A, B, C, Grilos (G), Quilombo (Q) e Torres (T) . ${ }^{a}$ : espécie com distribuição ampla dentro da Mata Atlântica; ${ }^{b}$ : espécie com distribuição restrita a algumas poucas localidades na Mata Atlântica do sudeste; ' : espécie com distribuição ampla, dentro e fora da Mata Atlântica; ${ }^{d}$ : espécie introduzida; ${ }^{1}$ : espécie com reprodução terrestre; ${ }^{2}$ : espécie com reprodução associada a bromélias; ${ }^{3}$ : espécie com reprodução associada a ambiente aquático.

Table 1. Abundance of anuran species, total Abundance, Richness, and Equitativity (Shannon) of the anuran assemblage sampled in six areas at the Reserva Florestal de Morro Grande, Cotia, SP, Brazil. The asterisks mark species sampled fortuitously out of the study period. The abbreviations stands for the areas sampled at the Reserva do Morro Grande (MG): A, B, C, Grilos (G), Quilombo (Q), and Torres (T). ${ }^{a}$ : Widespread species inside Atlantic Forest; ${ }^{b}$ : species restricted to few localities at the southeastern Atlantic Forest; ${ }^{c}$ : widespread species inside and out Atlantic Forest Domain; ${ }^{d}$ : introduced species; ${ }^{1}$ : species with terrestrial reproduction; ${ }^{2}$ : species with reproduction associated to bromeliads; ${ }^{3}$ : species with aquatic reproduction.

\begin{tabular}{|c|c|c|c|c|c|c|c|c|}
\hline Família/espécie & Nome popular & MGA & MGB & MGC & MGG & MGQ & MGT & Total \\
\hline \multicolumn{9}{|l|}{ Brachycephalidae } \\
\hline Brachycephalus ephippium $^{\text {a,1 }}$ & pingo-de-ouro, sapinho-dourado & & & & 1 & & & 1 \\
\hline Brachycephalus hermogenesi ${ }^{\mathrm{b}, 1}$ & sapo-pulga & & & 3 & 4 & 6 & 5 & 18 \\
\hline \multicolumn{9}{|l|}{ Bufonidae } \\
\hline Bufo ornatus ${ }^{\mathrm{a}, 3}$ & sapo-cururu-pequeno, sapo-da-mata & 32 & 16 & 24 & 139 & 170 & 101 & 482 \\
\hline Bufo ictericus ${ }^{\mathrm{a}, 3}$ & sapo-cururu, cururuzão & 3 & 6 & 7 & 2 & 3 & 19 & 40 \\
\hline Dendrophryniscus brevipollicatus ${ }^{\mathrm{a}, 2}$ & sapinho-da-bromélia & & & 1 & & 1 & & 2 \\
\hline \multicolumn{9}{|l|}{ Hylidae* } \\
\hline *Dendropsophus microps ${ }^{\mathrm{a}, 3}$ & pererequinha & & & & & & & \\
\hline *Flectonotus fissilis ${ }^{\mathrm{b}, 2}$ & perereca-de-pulseira & & & & & & & \\
\hline${ }^{*}$ Hypsiboas bischoffi ${ }^{\mathrm{a}, 3}$ & perereca & & & & & & & \\
\hline *Scinax alter ${ }^{\mathrm{a}, 3}$ & perereca & & & & & & & \\
\hline *Scinax fuscovarius ${ }^{\mathrm{c}, 3}$ & raspa-cuia, perereca-de-banheiro & & & & & & & \\
\hline${ }^{*}$ Scinax perpusillus ${ }^{\mathrm{b}, 2}$ & pererequinha-de-bromélia & & & & & & & \\
\hline \multicolumn{9}{|l|}{ Leptodactylidae } \\
\hline Adenomera marmorata ${ }^{\mathrm{a}, 1}$ & rãzinha-piadeira & 10 & 7 & 6 & 2 & & 2 & 27 \\
\hline *Crossodactylus caramaschii ${ }^{\mathrm{b}, 3}$ & rãzinha-do-riacho & & & & & & & \\
\hline Cycloramphus acangatan ${ }^{\mathrm{b}, 1}$ & rã-cabeçuda & 1 & & 23 & 10 & 32 & 17 & 83 \\
\hline *Eleutherodactylus binotatus ${ }^{\mathrm{a}, 1}$ & rã-da-mata & & & & & & & \\
\hline Eleutherodactylus guentheri ${ }^{\mathrm{a}, 1}$ & rã-da-mata & 2 & 3 & & 3 & & 4 & 12 \\
\hline Eleutherodactylus juipoca ${ }^{\mathrm{c}, 1}$ & rã-da-mata & & & & 1 & & & 1 \\
\hline *Eleutherodactylus gr. lacteus ${ }^{\mathrm{a}, 1}$ & rã-da-mata & & & & & & & \\
\hline Eleutherodactylus parvus ${ }^{\mathrm{a}, 1}$ & rã-da-mata & & 1 & & 4 & & & 5 \\
\hline Leptodactylus ocellatus ${ }^{\mathrm{c}, 3}$ & $\begin{array}{l}\text { rã-manteiga, rã-mirim, rã- } \\
\text { paulistinha }\end{array}$ & & 5 & 3 & & & & 8 \\
\hline Macrogenioglottus alipioi ${ }^{\mathrm{a}, 3}$ & sapo & 7 & 4 & 3 & 3 & & 1 & 18 \\
\hline Physalaemus cuvieri ${ }^{\mathrm{c}, 3}$ & rã-chorona, rã-cachorro & & & & & 1 & & 1 \\
\hline Physalaemus olfersii ${ }^{\mathrm{a}, 3}$ & rã & 16 & 23 & 10 & & 4 & & 53 \\
\hline Proceratophrys boiei ${ }^{\mathrm{a}, 3}$ & intanha-pequena, sapo-de-chifre & 9 & 5 & 2 & 6 & 4 & 3 & 29 \\
\hline \multicolumn{9}{|l|}{ Microhylidae } \\
\hline Chiasmocleis leucosticta $^{\mathrm{a}, 3}$ & rãzinha-do-aguaceiro & & & & 4 & & & 4 \\
\hline Myersiella microps ${ }^{\mathrm{a}, 1}$ & rãzinha-bicuda & & & & & & 23 & 23 \\
\hline \multicolumn{9}{|l|}{ Ranidae } \\
\hline Rana catesbeiana $^{\mathrm{d}, 3}$ & rã-touro & & & & & 1 & & 1 \\
\hline Abundância total & & 80 & 74 & 82 & 175 & 222 & 175 & 808 \\
\hline Riqueza & & 8 & 10 & 10 & 11 & 9 & 9 & 18 \\
\hline Equitatividade & & 0,81 & 0,86 & 0,82 & 0,39 & 0,39 & 0,64 & 0,54 \\
\hline
\end{tabular}

http://www.biotaneotropica.org.br 
Tabela 2. Abundância das espécies de lagartos e serpentes amostrados nas diferentes áreas da Reserva Florestal de Morro Grande, Cotia - SP, Brasil. Com asterisco espécies amostradas fortuitamente fora da época do estudo. As abreviaturas correspondem as áreas amostradas na Reserva do Morro Grande (MG): A, B, C, Grilos (G), Quilombo (Q) e Torres (T). ${ }^{a}$ : espécie com distribuição ampla dentro da Mata Atlântica; ${ }^{b}$ : espécie com distribuição restrita a poucas localidades na Mata Atlântica do sudeste; ${ }^{c}$ : espécie com distribuição ampla, dentro e fora da Mata Atlântica.

Table 2. Abundance of lizard and snake species sampled at the different areas at the Reserva Florestal de Morro Grande, Cotia - SP, Brazil. The asterisks mark the species sampled fortuitously out of the study period. The abbreviations stands for the areas sampled at the Reserva do Morro Grande (MG): A, B, C, Grilos (G), Quilombo (Q), and Torres (T). ${ }^{a}$ : Widespread species inside Atlantic Forest; ${ }^{b}$ : species restricted to few localities at the southeastern Atlantic Forest; ${ }^{c}$ : widespread species inside and out Atlantic Forest Domain.

\begin{tabular}{lllllllll}
\hline Família/espécie & Nome popular & MGA & MGB & MGC & MGG & MGQ & MGT & Total
\end{tabular}

\section{LAGARTOS}

\section{Gymnophthalmidae}

Colobodactylus taunayi ${ }^{\text {a }}$

Ecpleopus gaudichaudii ${ }^{\text {a }}$

Heterodactylus imbricatus ${ }^{\text {a }}$

\section{Leiosauridae}

Enyalius perditus ${ }^{\mathrm{b}}$

Teiidae

*Tupinambis merianae ${ }^{\mathrm{c}}$

\section{Abundância total}

\section{SERPENTES}

\section{Colubridae}

Echinanthera cyanopleura ${ }^{\text {a }}$

$$
\begin{aligned}
& \text { lagarto } \\
& \text { lagarto } \\
& \text { lagarto }
\end{aligned}
$$

camaleão

teiú, tiú

$\begin{array}{llll}30 & 12 & 7 & 24\end{array}$

1

60

2

$\begin{array}{lll}1 & 1 & 2\end{array}$

$\begin{array}{lllllll}3 & 9 & 4 & 13 & 11 & 8 & 48\end{array}$

\section{Elapidae}

Micrurus corallinus $^{\text {a }}$

coral-verdadeira

jararaca
Viperidae

*Bothrops jararaca ${ }^{\text {a }}$

Abundância total 